\title{
From outbreak of COVID-19 to launching of vaccination drive: invigorating single-use plastics, mitigation strategies, and way forward
}

\author{
Krishna Priyadarshini Das ${ }^{1} \cdot$ Deepika Sharma $^{1} \cdot$ Sampa Saha $^{1} \cdot$ Bhabani K. Satapathy $^{1}$ (D) \\ Received: 20 May 2021 / Accepted: 14 August 2021 / Published online: 3 September 2021 \\ (C) The Author(s), under exclusive licence to Springer-Verlag GmbH Germany, part of Springer Nature 2021
}

\begin{abstract}
The unforeseen outbreak of the COVID-19 epidemic has significantly stipulated the use of plastics to minimize the exposure and spread of the novel coronavirus. With the onset of the vaccination drive, the issue draws even more attention due to additional demand for vaccine packaging, transport, disposable syringes, and other allied devices scaling up to many million tonnes of plastic. Plastic materials in personal protective equipment (PPE), disposable pharmaceutical devices, and packaging for ecommerce facilities are perceived to be a lifesaver for the frontline healthcare personnel and the general public amidst recurring waves of the pandemic. However, the same material poses a threat as an evil environmental polluter when attributed to its indiscriminate and improper littering as well as mismanagement. The review not only highlights the environmental consequences due to the excessive use of disposable plastics amidst COVID-19 but also recommends mixed approaches to its management by adopting the combined and step-by-step methodology of adequate segregation, sterilization, sanitization activities, technological intervention, and process optimization measures. The overview finally concludes with some crucial way-forward measures and recommendations like the development of bioplastics and focusing on biodegradable/bio-compostable material alternatives to holistically deal with future pandemics.
\end{abstract}

Keywords COVID-19 · Plastic materials · PPE kit · Environmental consequences $\cdot$ Policy recommendations

\section{Preamble}

In the face of the sudden advent of the COVID-19 pandemic, plastic waste management is one of the most serious environmental concerns, as the rapidly growing production of singleuse plastic (SUP) products (gloves, masks, etc.) overwhelms the world's ability to deal with them. Currently, commodity

Highlights - Resurgence of single-use plastic materials in COVID-19 escalation vis-à-vis demand for diagnostic requirements for global vaccination drive is discussed

- Environmental consequences and foreseeable technologically assisted mitigation strategies are highlighted

- Optimal waste management strategies adopted policy frameworks and some implementable way forward steps are discussed

Responsible Editor: Lotfi Aleya

Bhabani K. Satapathy

bhabaniks@gmail.com; bhabani@mse.iitd.ac.in

1 Department of Materials Science and Engineering, Indian Institute of Technology Delhi, Hauz Khas, New Delhi 110016, India plastic and other polymer-based products are being rigorously used as protective materials and in other related applications, thereby escalating not only the global need for plastics/ polymers but also the threat of additional unprecedented solid waste hazards. In view of this scenario, the questions that confront the material designers and environmental experts in order to mitigate the exorbitant plastic waste generation are as mentioned below.

(a) Can the waste to energy approach be implemented?

(b) Can the antiviral surface be integrally developed on bioplastics/biodegradable plastics/agro-based plastic as substrates?

(c) Can COVID-19 waste be recycled post sterilization/ sanitization by UV treatment/corona/plasma treatment cost-effectively?

(d) Can the packaging technology of sanitization products for such health exigencies be high-end technology-assisted?

Conceptually such material issues need to be addressed following concerted strategies by resorting to plastic material 
manufacturers, raw material producers, material technologists, and material processing experts, vis-a-vis life cycle analysis approach-based decision making to minimize ecological footprints. In this time of uncertainty and gloom, despite the launching of many versions of vaccines to counter COVID19 , the challenge before mankind remains still a pin-pointed threat. The intensity of such a threat may be easily comprehended from the fact that there are more than nearly $7 \times 10^{9}$ people to be vaccinated where for example, the storage of the vaccine, the disposable syringes, the hand gloves to be used by the health workers reaching across the length and breadth of every stratum of society is going to be a humongous task.

Moreover, most parts of the world are now experiencing the so-called second wave of COVID-19 since early 2021 due to the rapid spread of various mutations (including the more recent form of delta variant) of deadly coronavirus across countries such as the USA, India, Germany, the UK, and Brazil. The increase in the number of infected individuals and the death rate in the second wave has wreaked havoc, worldwide, and the statistics indicate the outcomes to be worse than in 2020. Moreover, an enormous global increase in the use of medical equipment has simultaneously enhanced the rate of generation and reckless disposal of medical waste (along with generalized single-use plastics (SUP) such as personal protective equipment (PPE)). For instance, as estimated by the central pollution control board (CPCB), the average generation of COVID-19-related biomedical waste in India shot up from 75 tonnes per day in March 2021 to 203 tonnes per day in May 2021, attributing to the sudden rise in the number of infected individuals (Krishnakumar 2021). Thus, the current global status calls for the implementation of stricter regulations (in terms of monitoring, treatment, and disposal of medical waste), not only at the national level but also at the international level, in order to control and improvise the flaws in the present plastic-based medical waste management scenario.

Since the outbreak of the COVID-19 pandemic, some reports and reviews on management and possible strategies that can be adopted to ensure sustainable solid waste practice pertaining to the issue of containment of virus spread vis-avis minimizing ecological footprints have come up. For example, Sharma et al. have discussed the critical concerns and worldwide challenges faced by the waste management sector during the COVID-19 pandemic (Sharma and Satapathy 2020). The report suggested innovative solutions to fill existing loopholes in the current waste management system and its viable modifications to avoid and tackle similar problems in probable future pandemics holistically. Similarly, Silva et al. have analyzed the impact of the COVID-19 pandemics on pollution concerns due to plastic and its potential ramifications on human health and the environment considering the short and long-term consequences (Silva et al. 2021).
The article further sheds light on global challenges and potential mitigation approaches to overcome them. In another summative report conducted by Kulkarni et al., the prevailing municipal solid waste (MSW) management practices in a few developed and developing countries, which emphasizes the entire MSW treatment cycle from waste collection to disposal, has been commented upon (Kulkarni and Anantharama 2020). Similarly, Tripathi et al. have discussed the effect of COVID-19 on the generation, recycling, and management of solid waste while highlighting the potential strategies taken by different countries to handle solid waste (Tripathi et al. 2020). In an interesting report, Rume et al. reviewed the negative and positive environmental impacts of the current ongoing pandemic, where the adverse consequences like generation of a huge amount of hospital waste, unprecedented use and disposal of the contaminated mask, gloves, and disinfectants, and aspects related to the burden of untreated hazardous medical waste repeatedly endangering the environment has been discussed (Rume and Islam 2020).

With this background understanding of the scenario, it is evident that the revitalization of SUPs and plastic, in general, have been thoroughly put into scrutiny, despite its timely intervention and massive utilization in such an emergency where it so far has proved to be a boon than a bane as perceived by a section of technologists and environmentalists unilaterally. However, it is also crucial to take the disposal, recycling, sterilizing, and management of these classes of solid waste into consideration to sustainably ensure its usage in dealing with such a crisis globally. So far, most of the recommendations did not even foresee or address the pandemic era and presented conflicting reports in one or more cases, which lead to an unclear picture of the whole scenario.

Therefore, this review not only discusses the merits and demerits of SUPs during the COVID-19 pandemic but also highlights the forthcoming challenges and issues as the world inches ahead towards the universal vaccination drive. Contextually, the current report also focuses on the surge in production among packaging sectors, associated negative environmental impacts, and probable challenges in accordance with the aftermath of the ongoing pandemic. Further, the review summarizes several policy recommendations associated with future outlook and research directions to lead to a sustainable waste management approach during and after the outbreak. Besides, countries around the world have started the vaccination program in a phased manner this year. In this connection, the environmental repercussions of the use of SUP syringes and vials in extremely large numbers (leading to $\sim 10^{9}$ tonnes of additional waste as per a conservative estimate) for these massive COVID-19 vaccinations are yet to be explored. Therefore, this article not only delves deeper into the impact of the massive and unprecedented increase of plastic waste associated with the COVID-19 prevention protocol but also the likely consequences of the worldwide COVID-19 
vaccination program on environmental sustainability vis-a-vis feasible technological intervention-related concepts, strategies, and practices to be followed and some remarks for the way forward.

\section{Introduction}

The rapid spread of contagious novel coronavirus, identified as COVID-19, has currently emerged as a global catastrophe. The total number of reported confirmed coronavirus cases linked to the novel coronavirus has now crossed the $149 \times$ $10^{6}$ mark (Worldometer 2021). Initially, the coronavirus outbreak was reported in Wuhan city, Hubei Province, China, last December 2019, and announced as a pandemic on the 11th of March 2020 by World Health Organization (WHO) (Taylor and Johnson 2020). It resulted in a complete lockdown in most countries. In a virtual media briefing held on the 13th of April 2020 in Geneva, WHO chief Tedros Adhanom Ghebreyesu declared novel coronavirus (COVID-19) to be ten times deadlier than the 2009 swine flu (H1N1) pandemic (The Economic Times 2020). This infectious disease was allegedly originated from animal sources and is transmitted via aerosols and human contact, causing acute respiratory syndrome (Shereen et al. 2020). Researchers all over the world are progressively aiming to develop effective aids to minimize and/or cease the virus spread (WHO 2020e).

Amid this painful scenario, plastic plays a crucial role in protecting people from the deadly coronavirus, especially the frontline warriors like doctors, nurses, and various healthcare workers fighting the current pandemic. Moreover, it is mandatory for every healthcare personnel to wear PPEs as a general preventive measure while dealing with suspected, symptomatic, and/or asymptomatic COVID-19 carriers. PPEs offering protection against the current pandemic commonly comprise gloves, gowns, head, and shoe covers, masks and respirators, goggles, and face shields. However, surgical gloves, masks, gowns, heads, and shoe covers are usually made of disposable SUPs. As per WHO records, shared on $3^{\text {rd }}$ March 2020, $30 \times 10^{6}$ gowns, $1.6 \times 10^{6}$ goggles, $89 \times 10^{6}$ medical masks, and $76 \times 10^{6}$ gloves are monthly needed for healthcare professionals to outlive the pandemic (WHO 2020a). Moreover, the neurotic mindset developed among individuals owing to the rapid transmission of the highly contagious virus has also escalated the use of PPEs, gloves, and hand sanitizers on a daily basis. Thus, reportedly, $65 \times 10^{9}$ gloves and $129 \times 10^{9}$ face masks are consumed worldwide on a monthly basis (Prata et al. 2020).

The current upsurge in demand for SUP materials and medical supplies in 2020 has significantly escalated from the previous year. A recent case study in Wuhan reported that maximum infectious health care waste is being produced by confirmed COVID-19 patients $(\sim 3.2 \mathrm{~kg} /$ patient $)$ and minimum by the suspects $(\sim 0.1 \mathrm{~kg} /$ patient) (Wang et al. 2021). The global plastic packaging market is projected to grow $5.5 \%$ annually, from about $\$ 909.2 \times 10^{9}$ in 2019 to about $\$$ $1,162.6 \times 10^{9}$ by 2021 , attributing to the epidemic response (Markets and Markets, 2020). Moreover, the mismanagement in the disposal of PPEs may contribute to global plastic contamination and incited potential trajectories of COVID-19 spread. The proposed threat is further triggered by overpopulated and polluted areas and/or nations. Such a drastic increase in consumption of SUPs has escalated the rate of plastic waste production and is thus, the most challenging concern in the present scenario. Reportedly, the volume of contaminated medical waste was enhanced by about six hundred percentage, that is, from 40 tonnes per day to 240 tonnes per day, during the pandemic period, in Hubei Province, China (ADB 2020). Furthermore, the average amount of plastic waste being generated increased from $\sim 2115$ tonnes per day in 2019 to $~ 3432$ tonnes per day in between 3 months(January to April 2020) in Bangkok alone (Tanakasempipat 2020). Meanwhile, COVID-19 pandemicrelated medical waste being produced per day has outreached to $\sim 600 \mathrm{~kg}$ in India, which is approximately $10 \%$ more waste as compared to pre-pandemic waste (Ramteke and Sahu 2020). Hence, there is an urgent need to adopt radically new approaches for reducing plastic consumption, such as recycling and reusing plastic products and comprehensively managing plastic waste. The effective waste management of medical and household waste can be practiced via appropriate collection, identification, segregation, storage, transportation, handling, and disposal, as well as through standard sterilization, personnel protection, and proper training program.

In particular, PPE and other plastic-based medical devices have loomed as a safeguard to protect the health and safety of various individuals during the pandemic. However, a fair assessment of the pros and cons, handling and mishandling, and associated environmental impacts during and post the COVID-19 pandemic is required. Thus, the paper reflects on the positive and negative roles of plastic in the management of the COVID-19 pandemic, the associated socio-environmental problems. The current review also meticulously summarizes numerous safer practices and some technology-assisted mitigation strategies to support policymakers and legislative bodies to address the current challenges of plastic waste disposal during and aftermath of the pandemic

\section{Transmission dynamics, surface interaction, and viability of COVID-19}

The influence of various virus and host factors on the pathogenesis of COVID-19 is schematically summarized in Fig. 1 while the origin of the resembling viruses with their origin, entry receptors, and mode of transmission are detailed in 
Table 1. A representative structural schematic and microscopic image of a typical COVID-19 virus are shown in Fig. 2. Before discussing the role of plastic in a pandemic scenario, various modes for transmission of COVID-19 virus via plastics and adsorption mechanisms on different inanimate surfaces are elaborately discussed. Moreover, for efficient management of plastic-based waste from households, streets, quarantine centers, or hospitals, the lifecycle of the virus, its transmission, and control pathways are briefly discussed in the subsequent sections.

\section{Mode of transmission}

The transmission of COVID-19 via various plastic surfaces is illustrated in Fig. 3. The droplet transmission typically occurs via direct, indirect, or close contact (within $\sim 1 \mathrm{~m}$ ) with the infected individual through their contaminated salivary and respiratory secretions (Jayaweera et al. 2020) (Rahman et al. 2020). Indirect transmission involves contact of a susceptible human or animal with inanimate objects or surfaces contaminated by an infected individual (fomite transmission). Thus, COVID-19 can also be transmitted by Faecal-Oral Route, i.e., through a contaminated environment (Castañ et al. 2021). However, airborne transmission occurs via microbes present in the nuclei of the fine droplets $(<5 \mu \mathrm{m}$ in diameter), which are formed as a result of the evaporation from the surface of larger droplets. Such microbes remain airborne for a long duration and, thus, can be transmitted over distances $>1 \mathrm{~m}$ (Jayaweera et al. 2020) (Kaur et al. 2021). So, wearing face masks offers protection against aerosols (Sterr et al. 2021).

\section{Surface interactions and persistence of coronavirus on various materials surfaces}

Apart from human-to-human transmissions, the respiratory droplets carrying the virus that fall on material surfaces or ground also act as a potential source of transmission as the virus tends to remain viable on the exposed surfaces for a considerable duration. Based on the sustainability of viruses on different surfaces, the choice of materials in medical and PPE should be carefully weighted. Warnes et al. scrutinized various types of human coronavirus on the surfaces of common materials. In the study, $\sim 20 \mu$ of infected cell lysate was applied on $\sim 1 \mathrm{~cm}^{2}$ surfaces of test specimens, followed by incubation at $\sim 21{ }^{\circ} \mathrm{C}$ and $\sim 30-40 \%$ relative humidity. The results showed that steel, stainless steel, silicone rubber, glass, ceramics, polyvinyl chloride (PVC), and Teflon kept the virus active for 5 days (Warnes et al. 2015). Doremalen et al. also reported a comparative analysis of the stability of both SARCOV and COVID-19 on various surfaces and in aerosols. The viruses were exposed to the steel, cardboard, plastic and other test surfaces followed by incubation at $\sim 21-23{ }^{\circ} \mathrm{C}, \sim 40 \% \mathrm{RH}$ for 7 days. Further, the aerosol stability was estimated by aerosolizing the virus in a stationary rotating drum at $\sim 65 \%$ $\mathrm{RH}$ and incubation at $\sim 21-23^{\circ} \mathrm{C}$ for $\sim 3 \mathrm{~h}$. COVID-19 virus was observed to be more stable on stainless steel and plastic (polypropylene) $(\sim 72 \mathrm{~h})$ than cardboard $(\sim 24 \mathrm{~h})$ and copper surfaces $(\sim 4 \mathrm{~h})$. Further, the deadly virus exhibited viability of $\sim 3 \mathrm{~h}$ in aerosols (van Doremalen et al. 2020) (Sharma et al. 2021a). Chin et al. reported that the persistence of coronavirus on various infected surfaces is dependent on environmental factors. The authors reported the absence of any infectious

Table 1 A brief summary and comparison of three highly pathogenic human coronaviruses (severe acute respiratory syndrome coronavirus (SARS-CoV), Middle East respiratory syndrome coronavirus (MERS-

CoV) and coronavirus disease 2019 (COVID-19)) on the basis of their phylogenetic origin, basic demographic information, and associated events

\begin{tabular}{|c|c|c|c|c|}
\hline Pandemics & SARS-CoV & MERS-CoV & COVID-19 & References \\
\hline Place of origin & $\begin{array}{l}\text { Foshan, Guangdong, } \\
\text { China }\end{array}$ & Saudi Arabia & Wuhan, Hubei, Province, China & (da Costa et al. 2020) \\
\hline Date of emergence & Nov 2002 & June 2012 & December 2019 & (da Costa et al. 2020) \\
\hline $\begin{array}{l}\text { Entry receptor in } \\
\text { human }\end{array}$ & $\begin{array}{l}\text { Angiotensin-converting } \\
\text { enzyme } 2 \text { (ACE-2) }\end{array}$ & $\begin{array}{l}\text { Dipeptidyl } \\
\text { peptidase-4 } \\
\text { (DPP4) }\end{array}$ & $(\mathrm{ACE}-2)$ & $\begin{array}{l}\text { (Lu et al. 2020) (Wang } \\
\text { et al. 2008) (Li et al. } \\
\text { 2020) }\end{array}$ \\
\hline $\begin{array}{l}\text { Mode of } \\
\text { transmission }\end{array}$ & $\begin{array}{l}\text { Droplet contacts with } \\
\text { the infected } \\
\text { individual }\end{array}$ & $\begin{array}{l}\text { Respiratory droplets, } \\
\text { contaminated } \\
\text { fomites }\end{array}$ & $\begin{array}{l}\text { Droplet contact with an infected individual (even if } \\
\text { asymptotic one), aerosol transmission, blood-borne } \\
\text { transmission, child-mother, and sexual transmission } \\
\text { contaminated fomites, oral-fecal }\end{array}$ & $\begin{array}{c}\text { (Shashank et al. 2021, } \\
\text { Karia et al. 2020) }\end{array}$ \\
\hline Incubation period & 4 days ( $~ 1-13$ days) & 5 days ( $\sim 2-15$ days $)$ & 5 days $(2-14$ days $)$ & - \\
\hline $\begin{array}{l}\text { Countries and } \\
\text { territories } \\
\text { affected }\end{array}$ & 29 & 27 & 268 & (Al-Qahtani 2020) \\
\hline Current status & Completely controlled & - & Ongoing pandemic & - \\
\hline Fatality ratio & $9.5 \%$ & $34.4 \%$ & $4.4 \%$ & (Petrosillo et al. 2020) \\
\hline
\end{tabular}


Fig. 1 Influence of various virus and host factors on the pathogenesis of COVID-19

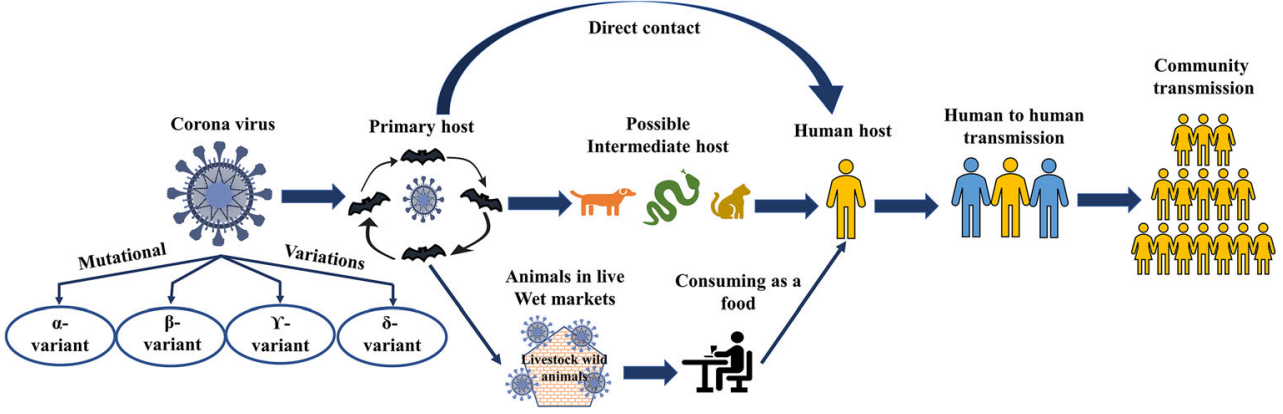

virus on glass and banknote surfaces beyond 4 days ( $\sim 96 \mathrm{~h}$ ) and on stainless steel and plastic surfaces post 7 days of exposure (Chin et al. 2020). In a study, Kampf et al. summarized the persistence of COVID-19 on various types of inanimate surfaces like metal, glass, or plastic and reported the presence of the virus from $2 \mathrm{~h}$ to 9 days post-exposure (Kampf et al. 2020). The estimated survival time of the coronavirus on different surfaces is summarized in Fig. 4.

The adsorption mechanism of COVID-19 on various environmental surfaces is not well reported. However, it is assumed to be driven by attractive electrostatic parameters such as $\mathrm{pH}$, isoionic or isoelectric point (pI), and ionic strength, which facilitates in leading to weak interactive forces (e.g., van der Waals forces) and hence induces binding of protein $\mathrm{S}$ to solid surfaces. Moreover, the survival of the virus is reported to be higher on non-porous material surfaces such as stainless steel, latex, plastic, and glass than porous material surfaces like paper and cotton (Aydogdu et al. 2021). In a study, Rajneesh et al. (Bhardwaj and Agrawal 2020) reported the effectiveness of larger hydrophilic surfaces in reducing the droplet drying time and hence are considered to be appropriate surfaces for designing masks, PPEs, and other accessories that encounter frequently exposed surfaces. Reportedly, a reduction in contact angle by $\sim 10^{\circ}$ for N95 masks and PPE bodywear reduces the chances of COVID-19 infection by 38\% (Bhardwaj and Agrawal 2020). Thus, COVID-19 infection can be significantly reduced by tailoring the surface wettability and droplet drying time. Topographic irregularities, texture, and roughness of the inanimate surface also play an influencing role in virus deposition (Tiwari et al. 2006) (Hossain et al. 2020). Reducing surface roughness and creating a textured surface at the micro/nanoscale can lead to a reduction in the availability of contact area for viral adhesion and thereby reduce surface stability for COVID-19.

The infected respiratory droplets primarily comprise of saliva, active virus, and mucus. Further, the shape, size, and composition directly influences the viscosity and flow properties of the droplets, thereby governing their persistence on the material surface. The viability of the virus on various surfaces is also dependent on the nature of interfacial interaction between the substrate and the infected respiratory droplet. The wettability of various material surfaces is represented in Fig. 5. Reportedly, the hydrophilic surfaces with contact angle $(\theta)$ $<90^{\circ}$ promote the interfacial spread of the liquid. However, interfacial retention of droplet shape was observed for relatively more hydrophobic surfaces with $\theta>90^{\circ}$ (Bracco and Holst 2013). Thus, infected droplets can be easily removed from the hydrophobic surfaces using a sanitizer. Understanding the usages of waterproof materials such as plastics is ideally preferred to avoid contact with infected blood, fluids, and body secretions.

\section{The role of plastics in the pandemic scenario}

The extended prevalence of COVID-19 beyond 2020 not only posed a grave threat to humanity but also presented challenges to control the transmissibility of the virus among hygiene
Fig. 2 a Schematic representation of COVID-19 virion comprising of structural proteins labeled as envelope (E), spike (S), membrane (M), and nucleocapsid $(\mathrm{N})$ genes and $\mathbf{b}$ appearance of corona virus under a transmission electron microscope (source: Microbe Notes 2020)

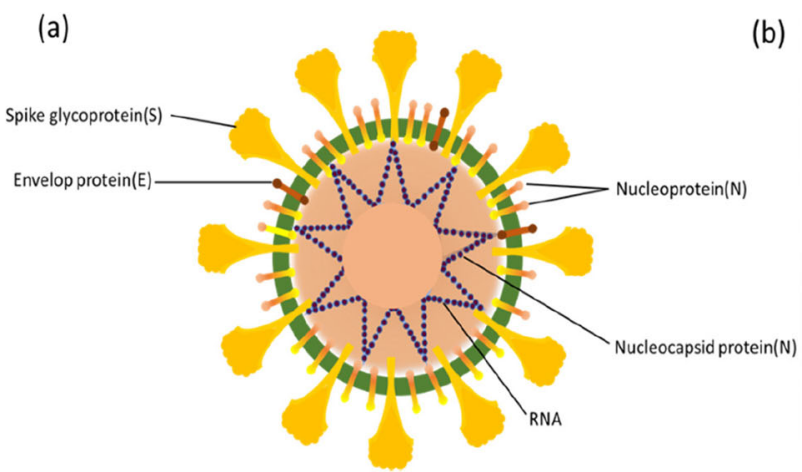

(b)

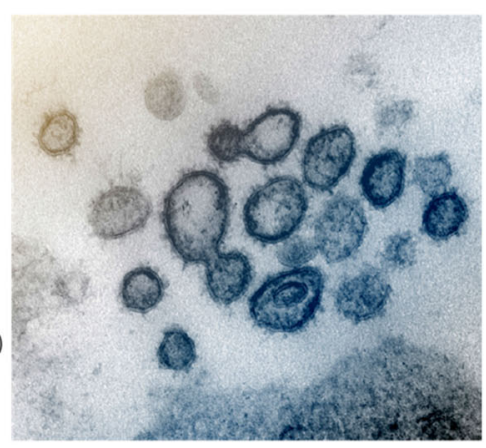


Fig. 3 Different modes of COVID-19 transmission

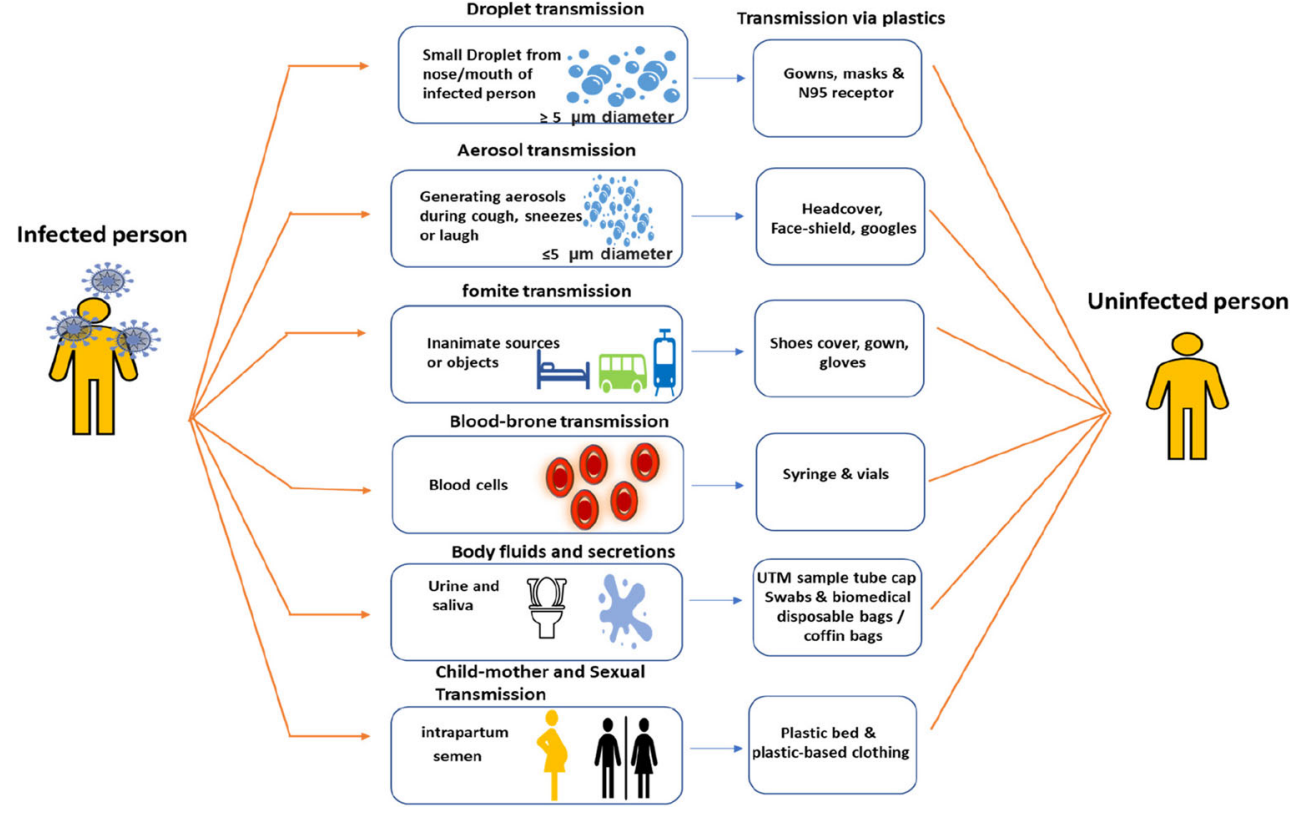

compromised communities. Moving beyond the hygiene compromised classes are the medical professionals getting directly exposed to COVID-19 through aerosols, respiratory droplets, and direct handling of contagious secretions like sputum, serum, blood, feces, etc.) of infected patients (Jayaweera et al. 2020) leading to the increased risk of asymptomatic and pre-symptomatic transmission. In such a scenario of gloom, the widespread use of plastic for health and hygiene concerns of healthcare workers and compromised communities became imminent and is obvious due to their cost-effectiveness, light-weightiness, flexibility easy availability, and easy processibility.

Plastic materials are mostly cost-effective, easily available, light-weight, flexible, and processible, and thus have

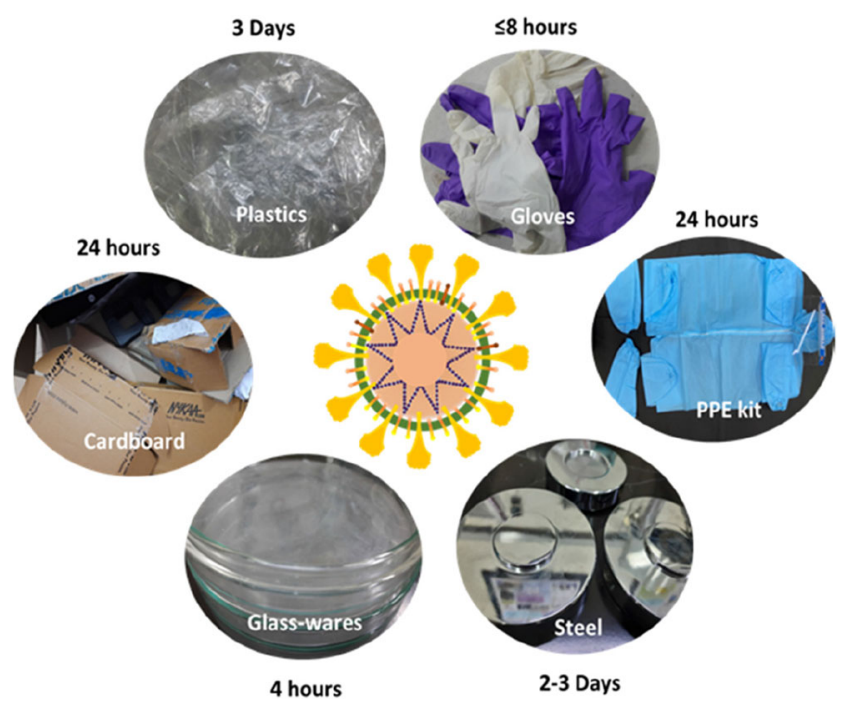

Fig. 4 Survival time of COVID-19 on various surfaces attained a pivotal status in modern society. For example, Ergo plastics are at the forefront of many modern advances owing to their genuinely revolutionary transformative capabilities in numerous emerging fields like biomedical, pharmaceutical, energy, packaging, fishery, and so on (Andrady and Neal 2009) (Narancic et al. 2020). It is due to this versatility that in the last 5 years, the overall plastic production increased from $\sim 300 \times 10^{6}$ to $\sim 368 \times 10^{6} \mathrm{~kg}$ globally (Tiseo 2021).

Plastics in the role of COVID-19 care comprise a whole class of complex polymers and copolymers, laminates, composites, and substrates that have been used in PPE, medical instruments, single-use medical devices, and in the packaging (consumer goods, pharmaceuticals) for e-commerce services to ensure and protect human well-being during the coronavirus epidemic. In addition, a specific group of plastics/ polymers are not only the most proficient and advantageous for packaging and transporting goods but also are environmental-friendly due to their inherent biodegradability properties apart from being light-weight, durable, low-volume, less expensive, and with good insulating properties (Sharma et al. 2020, Klemeš et al. 2020). Numerous studies have shown that the strength and flexibility of certain polymers, such as films and sheets, reduced the overall weight of a package, which otherwise would have been increased by four times, resulting in up to $60 \%$ more plastic waste (Klemeš et al. 2020; Vanapalli et al. 2021). The rapid surge of COVID-19 cases has also accelerated the use and consumption of plasticbased safety kits and packaging solutions. Such a situation has led to an abrupt and unprecedented rise in plastic production. To further emphasize the role of plastic in medical as well as ecommerce packaging applications is further elaborated in the following sections. 
Fig. 5 a Schematic representation for hydrophobic and hydrophilic interfaces and $\mathbf{b}$ contact angles of the respiratory droplet on various surfaces (Source: Bhardwaj and Agrawal 2020)

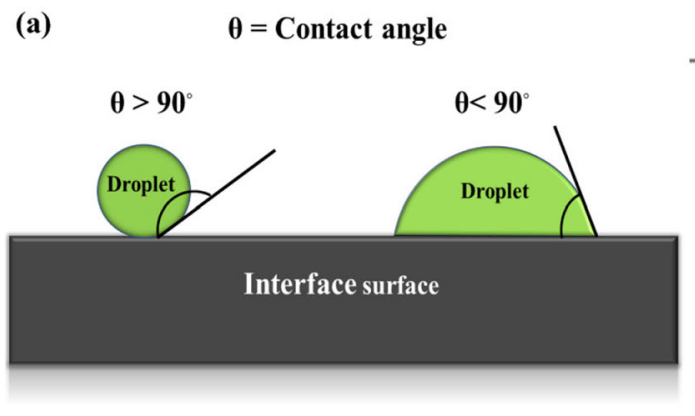

(b)

$\begin{array}{lc}\text { Glass } & 5^{\circ}-15^{\circ} ; 29^{\circ} \\ \text { Wood } & 62^{\circ}-74^{\circ} \\ \text { Stainless steel } & 32^{\circ} \\ \text { Cotton } & 41^{\circ}-62^{\circ} \\ \text { Smartphone screen } & 74^{\circ}-94^{\circ} \\ \text { N95 mask } & 97^{\circ}-99^{\circ} \\ \text { PVC-coated surface } & 80^{\circ}-84^{\circ}\end{array}$

\section{Plastics in medical COVID-19 care applications}

The major reasons for nosocomial and community transmission attribute to the lack of awareness and preparedness, the dearth of proper training on infection control strategies, and poor compliance with PPEs, for the sudden outbreak of infectious diseases (Blanchard 2007). The common risk factors for coronavirus spread are direct contact in therapy and physical examination of the infected patient, close contact with infectious body fluids and excretory products from infected individuals, cardiopulmonary resuscitation, suctioning of airways, and endotracheal intubation. When observed under an electron microscope, the size of the COVID-19 virus ranges from $\sim 70$ to $\sim 90 \mathrm{~nm}$ in diameter. However, virus-carrying Flugge droplets, usually produced by coughing and sneezing that are less than $5 \mu \mathrm{m}$ in size, can travel up to $4.5 \mathrm{~m}$, endangering health care workers who are not even directly involved in patient care (Dhand and Li 2020). As per the COVID-19 report- 82 by $\mathrm{WHO}$, the virus infected $\sim 22,073$ health care workers in 56 countries by 8th April 2020 (WHO 2020b). In order to minimize the virus spread, plastic-based safety kits and packaging solutions play a crucial role in the prevailing pandemic scenario.

Post COVID-19 outbreak, the demand for plastic products is continuously increasing due to growing hygiene concerns, personal protection, and healthcare purposes. The components of PPEs such as gowns, face cover, head cover, shoe cover, gloves, mask or respirators, earplugs or muffs, coveralls, vests, and other packing-shielding materials, and their basic material characteristics are summarized in Table 2. Currently, PPEs are widely being used not only in treatment centers but also in cleaning, maintenance, waste management, burials, and community care to reduce the risk of contamination. PPEs are exclusively made from SUPs and are crucial in the present battle due to the rapid surge of COVID-19 cases worldwide. Reportedly, the use of PPE kits exhibited a remarkable drop in the number of coronavirus cases in China (Cook 2020). However, the lack of availability of PPEs in Sweden resulted in COVID-19 spread among thousands of health care workers (Gunia 2020). Similarly, a report on the spread of Ebola infection among HCWs in Liberia, Sierra Leone, and Guinea from January 2014 to March 2015 deduced that health care personnel are $\sim 21-32$ times more likely to be infected with Ebola in comparison to the general public. This was attributed to multiple infection prevention and control failures and the lack of availability of adequate PPEs.

Functionally, the face masks covering both mouth and nose helps in preventing the spread of respiratory secretions via breathing, talking, sneezing, or coughing. Generally, coughing produces a comparatively larger number of droplets than are inhaled while breathing (Dhand and Li 2020). Reportedly, the volume of communicating pitch is proportional to the number of salivary aerosols ejected while speaking, irrespective of the language spoken (Asadi et al. 2019). Moreover, about $\sim 10 \mathrm{~min}$ of conversation, at a standard volume, of a healthy person with an asymptomatic infected individual exposes them to $\sim 6000$ aerosols, which are subsequently inhaled (Asadi et al. 2020). Therefore, maintaining a distance of at least $\sim 1 \mathrm{~m}$ and using a protective face mask as an aerosol filter when in close proximity of an infected individual is recommended (WHO 2020c). Therefore, the increase in demand for surgical masks escalated the production of facemasks worldwide. In order to address the cost, nonrenewable petrochemical-derived raw materials such as polyethylene (PE), polypropylene (PP) (Potluri and Needham 2005) are widely used in industries for producing the masks (Henneberry 2020).

\section{Household uses of SUPs as domestic precautionary measures to prevent COVID-19}

As is known, social distancing and lockdown as alternate approaches have been exceptionally effective in combating the virus spread. However, such lockdowns (complete closure) of eating places (restaurants and cafeterias) and other recreational joints/malls, across the globe led to escalated demand for home delivery services and thereby increasing the production rate of common packaging plastic materials. Plastic packaging has played an important role in food safety as it acts as a protective barrier for food from contamination, minimizes spoilage, and enhances shelf life. Consequently, numerous forms of plastic packaging, including Protective Packaging, Global E-Commerce Packaging, and Global Corrugated 
Table 2 Basic characteristics and common materials used in the fabrication of basic components of a typical plastic-based PPE

\begin{tabular}{|c|c|c|c|c|}
\hline S No. & Components of PP & Commonly used raw materials & Characteristics & References \\
\hline 1 & 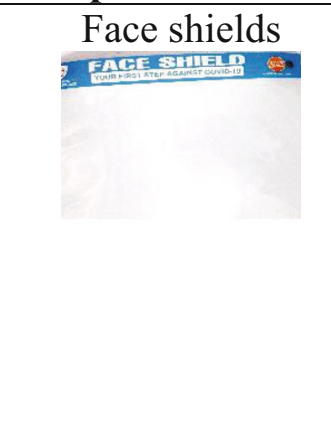 & $\begin{array}{l}\text { Polylactic acid (PLA) for the } \\
\text { headband and bottom } \\
\text { reinforcement bracket, } \\
\text { polyethylene terephthalate (PET) } \\
\text { and PVC/acetate for the } \\
\text { transparent visor, polyurethane } \\
\text { (PU), and ethylene-vinyl acetate } \\
\text { (EVA) for the foam pad and } \\
\text { bottom reinforcement bracket }\end{array}$ & $\begin{array}{l}\text { Excellent optical } \\
\text { property, impact strength, } \\
\text { good resistance to heat, } \\
\text { and chemicals enhance }\end{array}$ & $\begin{array}{l}\text { (Mostaghimi } \\
\text { et al., 2020, } \\
\text { Shokrani et } \\
\text { al., 2020). }\end{array}$ \\
\hline 2 & Goggles & Polycarbonate (PC) & $\begin{array}{l}\text { Thin, light-weight and } \\
\text { non-corrosive }\end{array}$ & $\begin{array}{l}\text { (Edwards, } \\
\text { 2020) }\end{array}$ \\
\hline 3 & $\begin{array}{l}\text { Face masks } \\
\text { (multi-layered) }\end{array}$ & $\begin{array}{c}\text { Polypropylene (PP) (nonwoven } \\
\text { and nanofibers), polyethylene } \\
\text { (PE) }\end{array}$ & $\begin{array}{l}\text { Non-toxic, breathable, } \\
\text { water-resistant, and } \\
\text { barrier properties against } \\
\text { particles and virus }\end{array}$ & $\begin{array}{l}\text { (Potluri and } \\
\text { Needham, } \\
\text { 2005) } \\
\text { (Henneberry, } \\
\text { 2020) }\end{array}$ \\
\hline 4 & PPE gowns & PP & $\begin{array}{l}\text { Light weight and good } \\
\text { barrier properties }\end{array}$ & $\begin{array}{l}\text { (Kilinc, } \\
\text { 2015) }\end{array}$ \\
\hline 5 & Gloves & $\begin{array}{c}\text { Natural rubber latex, Silicon, } \\
\text { neoprene, PVC, and PU }\end{array}$ & $\begin{array}{l}\text { Flexibility, dustrepellent, } \\
\text { and non-sticky }\end{array}$ & $\begin{array}{l}\text { (Yip and } \\
\text { Cacioli, } \\
\text { 2002) }\end{array}$ \\
\hline
\end{tabular}


6

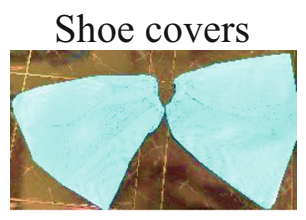

7

Headcovers

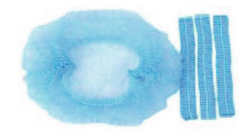

8

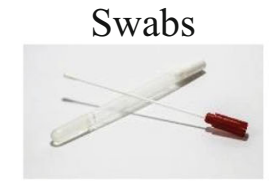

9

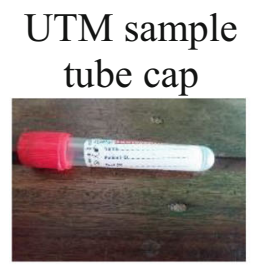

10
PP (non-woven)

PE film, PP film

PP (stick) and polyester (swab)

PP:

stick, polyester: absorbent

(Dhakate, 2020)
Excellent water resistance,(Parthasarathi

lightweight, cost-effective and

and non-toxic

characteristics

Thilagavathi, 2013)

Excellent air permeability, (Yesil and lightweight, and excellent Bhat, 2017) water-repellent characteristics

PE (cap) Airtight cap, leakage-proof (Dhakate,
2020)

Strength, stiffness, water resistance, and dimensional stability
(Dhakate, 2020) polyethylene (LLDPE), PP, poly (ethylene-vinyl acetate) (PEVA), EVA

Boxes, have increased tremendously (Ncube et al. 2020). Hyun et al. reported a $92.5 \%$ increase in online grocery purchases compared to 2019 in South Korea during the pandemic. Moreover, in countries like Germany, Vietnam, China, India, and Italy, online shopping has increased on an average from 12 to 57\% during the pandemic period (Hyun 2020). Furthermore, a market research firm, Rakuten Intelligence, has reported a $50 \%$ increase in the rate of online shopping in the USA during the lockdown period from March to midApril 2020 (Rattner 2020). This is attributed to the increase in demand for e-commerce packaging of groceries due to health and hygiene concerns, during the period of outbreak, and typically such packagings are usually made of films, foams, and/or multilayer plastics (UNEP 2018; Ncube et al. 2020).

\section{Escalated industrial production of plastics through the pandemic}

Most of the packaging companies that were nearly closing down before the coronavirus pandemic are currently back in the market as demand for this industry has surged dramatically. In order to address PPE storage, WHO urged many industries and governments to increase their manufacturing by 40\% (WHO 2020a). As reported by World Economic Forum 
(WEF), the daily usages of PPE kits have reached an astonishing level, even in the areas where the COVID-19 confirmed cases are relatively low (Konov 2020). As such, in February 2020, $\sim 1500$ gowns, $\sim 39,500$ facial masks, $\sim 4200$ filtering facepiece respiratory masks (FFP3), and $\sim 11,500$ medical gloves were used in the UK alone (Duer 2020). Furthermore, the projected demand for PPEs in the UK is speculated to range from $\sim 10$ to $\sim 16 \times 10^{6} \mathrm{PPEs} /$ day, apart from the current supply of $\sim 14 \times 10^{6}$ PPEs per day (Gray 2020). Similarly, according to data obtained from - BBC 2020 and LA Times, 2020, the demand for medical gloves in densely populated countries like China is expected to increase by $12.5 \%$ in 2020 (Gray 2020, Bengali 2020). Moreover, a leading market research firm, Freedonia Group, has also reported an $\sim 312 \%$ increase in demand for face shields amid the ongoing pandemic in the USA (BBC 2020, LA Times 2020). Since February 2020, China has reported a significant increase in face mask production by $450 \%$ in one month (from 20 to $110 \times 10^{6}$ ), and demand for N95 respirators has increased from $\sim 200,000$ to $\sim 1.6$ million (Bown 2020). In China alone, face mask production has climbed up to $\sim 116 \times 10^{6}$ in February 2020, which was $\sim 12$ times more than the production in January 2020 (OECD 2020). As the total population of China is $>1.4 \times 10^{9}$, a substantial gap has also been reported in the rising demand and consequent supply during the pandemic (Gray 2020). A similar trend is expected in countries where an increase in the COVID-19 cases is being reported, combined with safety awareness that has further upsurged the demand for PPE. According to the WWF estimation, in Italy alone, the monthly demand of the general public for PPE during the demodulation phase is estimated at $1 \times 10^{9}$ masks and $0.5 \times 10^{9}$ gloves (Cozier 2021). The conservative expansion of these figures for the entire European population leads to an estimated demand of 7.4 and $3.7 \times 10^{9}$ units of masks and gloves, respectively, per month (Pinto Da Costa et al. 2020). Moreover, it is reported that the demand for plastics rose by $\sim 40 \%$ in the packaging industry and $\sim 17 \%$ in other applications, which includes medical uses (Prata et al. 2020). Amid the coronavirus chaos, China escalated the facemask production capacity and is currently the primary producer of face masks worldwide. Moreover, global disposable mask sales are estimated to rise from $\sim 800 \times 10^{6}$ in 2019 to $\sim$ $166 \times 10^{9}$ in 2020 , as stated by the business consulting firm Grand View Research (Bratovcic 2021). The global disposable mask market is expected to accelerate with a CAGR of $\sim 5.4 \%$ to reach $\$ 28.8 \times 10^{9}$ by 2027 . The largest growth increases are expected in 2020 and 2021 at $~ 396.6 \%$ and 18.2\% CAGR respectively (Research and market 2020).

Not only two-thirds of the world population is experiencing myriad fatalities as a consequence of the COVID-19 pandemic but also it has brought out severe economic threats globally that may lead to irreversible losses. The vital need to boost PPE productivity is accompanied by herculean challenges such as research and implementation of appropriate measures for ensuring its quality and safe disposal. Besides, the price of crude oil has crashed to its all-time low (IEA 2020) due to the reduction of transportation facilities during the pandemicinduced lockdowns. The dramatic reduction in the demand for fuel such as petrol, diesel, and natural gases motivated the oil companies to shift their interest in booming plastic
Fig. 6 Impact of COVID-19 pandemic on plastic waste generation

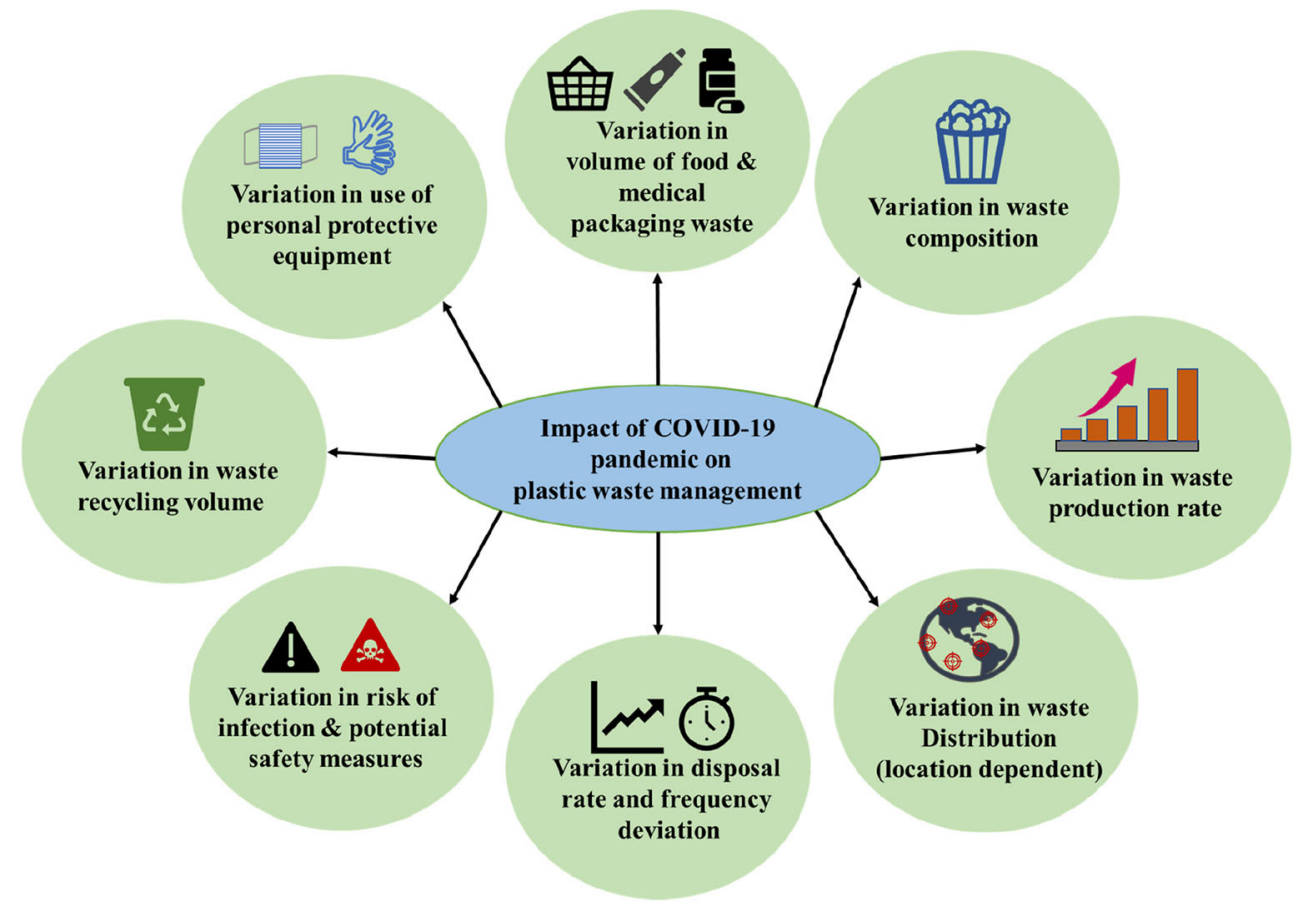


Fig. 7 Improper disposal of plastic-based medical waste

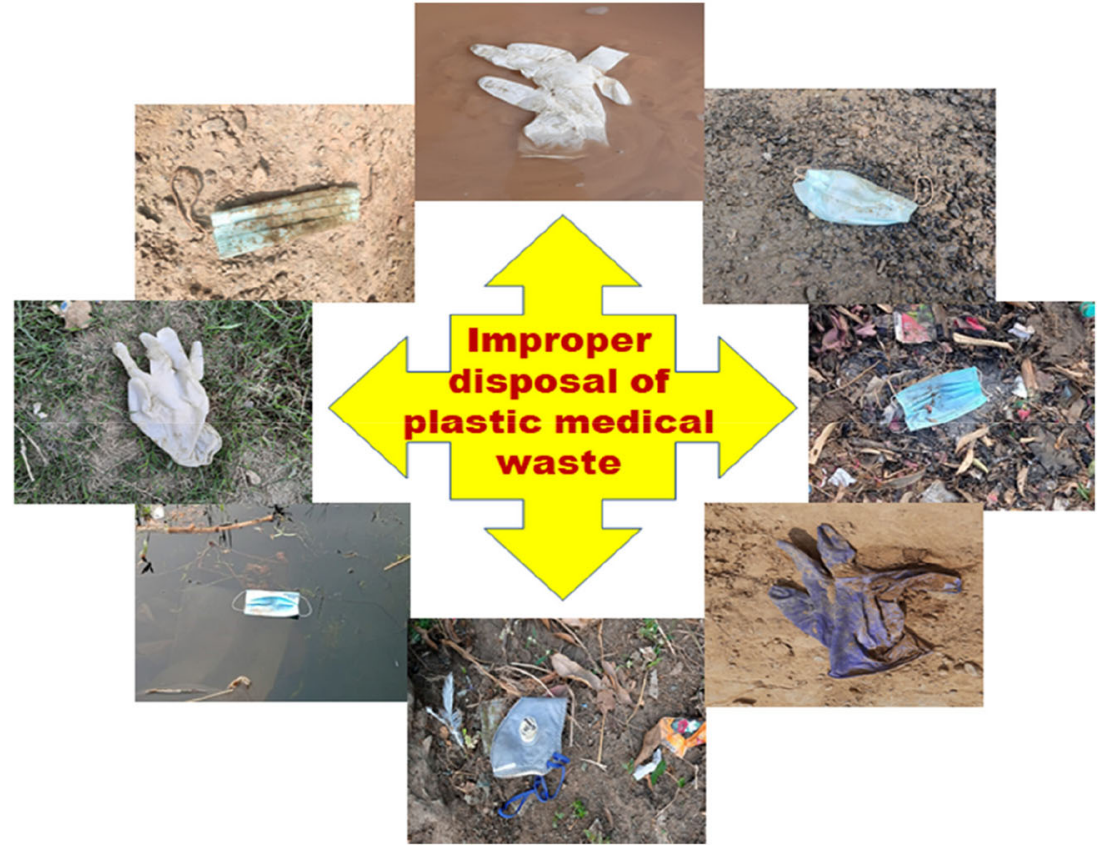

production, specifically for-profit concerns. Similarly, in the current scenario, manufacturing industries are choosing between plastic manufacturing and plastic recycling, and the former has loomed as an economically feasible option over the latter. Thus, the manufacturing industries are producing new classes of virgin plastics and thus further adding up to the unsustainable and mismanaged plastic waste generation at a much lower (trailing) plastic recycling rate. A significant reduction of $\sim 30-40 \%$ was reported for the consumption of recycled plastics in the southeast Asian countries and is attributed to the plummeting oil prices during the outbreak (BIR 2020). Further, increasingly subtle changes in plastic usage, such as replacing reusable bags with SUP-based bags as a precautionary measure, using disposable sanitizing wipes, and overusing hand sanitizers plastic bottles, are some of the extreme reactions of the public, exaggerating the production of plastics at a phenomenal rate of growth (Kalina and Tilley 2020). Thus, revocation of SUP usage bans and unprecedented use of PPE have created more serious problems in terms of effective waste management in the context of the increased production of plastic waste during the outbreak.

\section{Impact of COVID-19 pandemic on global plastic waste generation}

Globally, outbreaks have changed patterns of waste generation and disrupted the dynamics of international recycling markets. The impact of COVID-19 on the various factors attributing to plastic waste generation is schematically illustrated in Fig. 6. However, the major visible aspects that have enormously contributed in terms of human activities are (a) improper disposal of PPEs, (b) surge in e-commerce shopping and takeaway services, (c) reduction in recycling rate of SUPS due to pandemic, and (d) additional piling up of solid waste due to launching of worldwide vaccination drives.

\section{Improper disposal of PPEs}

The present COVID-19 outbreak has sparked the consumption and inappropriate management of plastic waste as the risk of infection among the healthcare professionals, essential personnel, and the general public increases without the use of masks, PPE kits, and hand sanitizers. The unprecedented use of plastic-based PPEs by frontline health workers and common citizens has escalated plastic waste generation globally. Reportedly, on 24th February 2020, when the coronavirus transmission rate was at a peak in Wuhan, the city produced $\sim 247$ tonnes per day of clinical waste, which is estimated to be six times the city's incineration capacity in the dedicated facility per day (Singh et al. 2020). Similarly, in Ahmedabad, India, the amount of hospital waste generated per day increased from $\sim 550-600 \mathrm{~kg}$ to $\sim 1000 \mathrm{~kg}$ during the first phase of lockdown (Somani et al. 2020). Moreover, cities like Hanoi, Manila, Kuala Lumpur, and Bangkok, experienced a similar rise and reportedly produced $\sim 154-280 \times 10^{6}$ tonnes of additional hospital waste per day than estimated before the pandemic (ADB 2020). Discarding surgical masks every day after use and empty bottles of hand sanitizer along with solid tissue papers have given rise to a massive trail of hospital waste mindlessly scattered in the environment, as illustrated in Fig. 7. The used face masks and coverings are usually found littering in public spaces (e.g., beaches, parking lots, roads) due to the public's incorrect disposal. According to a WWF 
report, "if even only one percent of the masks were disposed of inappropriately and perhaps dispersed in nature, this would result in as many as $10^{7}$ masks per month polluting the environment" (Monella 2020) . Considering the weight of each mask $\sim 4 \mathrm{~g}$, it would contribute to $\sim 40,000 \mathrm{~kg}$ of plastics waste in natural environments. In addition, the disposal of many plastic-based coronavirus RT-PCR (reverse transcription-polymerase chain reaction) testing kits after single-use, for hygiene concerns, has also escalated the rate of plastic waste production. Reportedly, India alone generated 14.5 tonnes per day of plastic waste associated with the RTPCR testing of coronavirus (Basu 2020). Furthermore, selfmedication with over-the-counter drugs (non-prescription drugs), increased the use of medication by the patients and the growing demand for popular immune-boosting drugs can potentially upsurge the production of pharmaceutical packaging waste such as bottles, blister packs etc. from both household and hospitals. Thus, the unprecedented global demands for these non-biodegradable SUPs are contributing towards environmental pollution that may in the long run lead to secondary health challenges.

In addition, during the outbreak, the entire Hubei Province in China saw a sharp surge $(\sim 370 \%)$ of hospital waste generation, which contains a substantial portion of plastic with a cumulative mass of $\sim 207 \mathrm{kt}$ (Klemeš et al. 2020). Following this trend, American consulting and research firm, Frost \& Sullivan, predicted that in just two months during a pandemic, the country could produce as much medical waste majorly comprising of plastic waste (mostly SUPs) as it would normally produce in one entire year (Duer 2020). A recent study by environment and social development organization (ESDO) reveals that at the end of the very first month of official lockdown, to prevent the spread of COVID-19, in Bangladesh, a total of $\sim 14,500$ tonnes of hazardous plastic waste, with $\sim 3076$ tonnes in Dhaka alone, has previously escalated due to increased use of disposable surgical face masks, latex gloves, hand sanitizers and polythene bags in communities and health care facilities (Parashar and Hait 2021). Reportedly, 40.9\% of this waste is derived from the excessive use of disposable polythene shopping bags used for carrying food items, $\sim 21.5 \%$ from polythene-based regular hand gloves, $\sim 20 \%$ from surgical hand gloves, $\sim 11.2 \%$ from the use of surgical face masks, and $\sim 6.4 \%$ from empty hand sanitizer bottles (Parashar and Hait 2021). In addition, 250 tonnes of hospital waste containing plastic-based gloves and surgical masks are generated from pathological testing laboratories, and hospitals with $\sim 1.1$ tonnes of SUPs waste were recorded (Parashar and Hait 2021). In South Korea, 295 tonnes of infectious plastic-based medical were reported from medicals $(61 \%)$, community treatment facilities $(5 \%)$, and isolation centers $(34 \%)$ for a period of one month from February to March 2020 (Rhee 2020).

\section{Surge in e-commerce shopping and takeaway services during the pandemic}

The pandemic has introduced not only a new form of consumer demand but also behavioral changes such as stockpiling of groceries as well as food items among the masses as well as panic buying, thereby resulting in an expected surge in requirements for plastic-packed items in many countries. For example, the growing trend of online purchasing and takeaway services has further exaggerated the plastic products demand. This is expected to grow with a sales growth rate of $\sim 40 \%$ in Spain and $\sim 14 \%$ in the USA (Duer 2020). The global plastic packaging market is projected to grow 5.5\% annually, from about $\$ 909.2 \times 10^{9}$ in 2019 to about $\$$ $1162.6 \times 10^{9}$ by 2021 , attributing to a typical consumer market response to the epidemic response (Markets and Markets, 2020). Furthermore, the food products with short shelf-life when stored without cold storage amenities resulted in an additional generation of waste. For instance, in New York City, the volume of solid waste produced from residential areas increased from $\sim 5$ to $\sim 30 \%$, whereas waste from industrial/commercial has come down, to as low as $50 \%$ (Waste Advantage 2020). Similarly, during the eight-week shutdown in Singapore that eased on 1st June 2020, an estimated $\sim 5.7 \times 10^{6}$ residents of the island city dumped an additional $\sim 1470$ tonnes of plastic waste originally produced from the disposal of food delivery and takeout packaging alone (UNCTAD 2020). In Thailand, plastic waste generation increased from $\sim 1500$ tonnes per day to $\sim 6300$ tonnes per day amid the pandemic and is also attributed to the soaring rise in takeaway services and online home delivery (Duer 2020). Therefore, the entire world is hit by a tidal wave of plastic waste, especially in the packaging form $(\sim 44.8 \%)$ and other medical waste $(\sim 13.2 \%)$ (UNCTAD 2020$)$. The common plastic packaging waste comprising of high-density polyethylene (HDPE), PP, LDPE, PS, PET, and medical equipment (PPE kits, mask, gloves, etc.) waste composed of PP, PE, or PVC mostly contributes to ongoing pandemic-based plastic pollution.

\section{Reduction in the recycling of single-use plastics during the pandemic}

Waste recycling is considered to be an effective means to address the escalated plastic pollution, conserve natural resources, and save energy (Ma et al. 2019). However, numerous countries have already put off waste recycling activities to reduce the risk of virus transmission. For example, many states in the USA are either downsizing or suspending the recycling programs, as the government is more concerned about the risk of transmission of the virus via recycling plants. Similarly, the UK, Italy, and other EU countries have banned infected residents from segregating waste (Zambrano- 
Monserrate et al. 2020). Such major disruption in the recycling activities is even more exaggerated in developing countries like India, Brazil, Kenya, Haiti, Guatemala, and Indonesia, attributing to the severe crisis of funds in such countries. The reduced collection, along with the dearth in market demand for recycled plastics, has motivated numerous informal recycling sectors in bearing the brunt of the pandemic (Shooshtarian et al. 2020a; Shooshtarian et al. 2021). Therefore, a significant reduction in plastic recycling in the context of unsustainable plastic production and an increase in waste production during a pandemic could pose a serious threat in a post-pandemic scenario.

Moreover, some SUPs are being widely used in commercial sectors, such as protective sheets/films on payment machines, chairs, balconies, desks, to prevent potential droplet transmission at work stations. Similarly, microfibre wipes for surface cleansing, SUP-based shoe protection covering, face and head shields, and cuffs are frequently being used in healthcare clinics and beauty salons. As the current COVID19 pandemic has drastically changed the dynamics of waste production and composition, it poses a tough challenge for policymakers, service providers, local authorities, and regulatory agencies. These theatrical alterations in the composition and volume of plastic waste during the pandemic have vowed distinct attention to resilient infrastructures and sustainable practices for the proficient disposal of plastics.

\section{Increase in plastic waste generation with the launching of a worldwide vaccination drive}

The beginning of 2021 was marked by the initiation of COVID-19 vaccination campaigns worldwide. Governments across the world are frantically trying to vaccinate as many people as possible to reduce and heal the damage caused by the sudden outbreak of coronavirus pandemic. Accordingly, the pace of production of vaccines has been accelerated to meet the global need of facilitating appropriate levels of immunization for the general population against COVID-19. As previously discussed, the unintended exorbitant usage of medical supplies to fight the COVID-19 has escalated the generation of plastic-based medical and household waste, ranging from PPEs to packaging. Furthermore, the intensity of the problem may further be aggravated with the commencement of global vaccination drives, leading to a substantial increase in the amount of rubber, glass, and plastic residues from vaccine containers in the environment. A cumulative estimate leads to the understanding that $\sim 1 \times 10^{9}$ tonnes of plastics/ rubbers and their associated solid wastes are likely to be generated as the wastes of the COVID-19 vaccinations. The various forms of disposables from the vaccination devices are syringes, droppers, vaccine bottle caps, gloves, etc. However, considering the average weight of syringe $\sim 5 \mathrm{~g}$, if the $7 \times 10^{9}$ are to be vaccinated in the coming future, $\sim 1 \times 10^{9}$ tonnes of plastic-based solid waste is likely to be generated post completion of COVID-19 vaccination when all the other peripheral plastic materials that are used aside from the syringe, like gloves, masks, etc. are included. For instance, according to On-Site Waste Technologies, a medical waste disposal company, if more than one dose is needed to confer immunity, $\sim 650 \times 10^{6}$ doses of COVID-19 vaccine will be required to inoculate the entire US population alone, which would create enough waste, i.e., $\sim 1.8$ times when wrapped around the Earth, to add to the destabilization of existing pollution challenges (Toussaint 2021). To impress upon such an estimate, a global cumulative statistic of the number of vaccine shots administered post-January 2021 is shown in Fig. 8. Moreover, various forms of disposables, such as syringes, droppers, vaccine vials, bottle caps, gloves, mobile storage containers (portable) with the inside temperature of -8 to $20^{\circ} \mathrm{C}$, are required for the storage, filling, and distribution of billions of doses of the vaccines worldwide. Therefore, the emerging challenge of mass vaccination and management of associated biomedical waste, involving hundreds of millions of individuals, needs to be addressed wisely. Furthermore, the real material challenge will potentially be the most significant among developing and low-income countries, which typically absorb the waste management costs with little consideration of the short- and long-term environmental and financial impacts due to lack of proper research and development prerequisites. Thus, if not equally important, the amount of non-degradable waste being generated through these immunization campaigns is a subject of serious environmental concern.

\section{Potential environmental consequences}

The worldwide lockdowns brought upon by COVID-19 resulted in numerous positive environmental changes such as clearer skies and cleaner rivers, but the same was not applicable for plastic waste management. Along with the far-reaching benefits of plastics, their massive consumption and waste mismanagement have led to serious environmental concerns, resulting in the addition of large-scale plastic waste into the environment. The implication of plastics and particulate pollution on the environment has been summarized and corroborated by erudite scholars in various literature (Thompson et al. 2009; Okunola et al. 2019) (Suthar et al. 2021) (Tabish et al. 2020). Some of these negative effects include the threat to marine animals, which is a significant component of the human food web. The water-resistant medical wastes made of plastic, such as masks, gloves, etc., once discarded end up in the water bodies (rivers, seas, and oceans) and landfills. The recent flooding in many south Asian countries such as India, Bangladesh, Bhutan, and Nepal escalated the persistence of plastics, as the likely infected litters tend to persist in the environment for decades. The inappropriate disposal of 


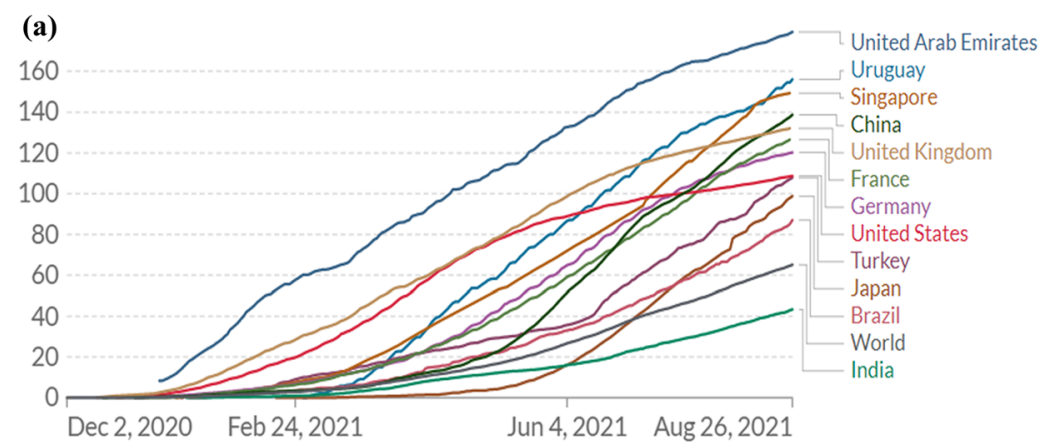

(b)

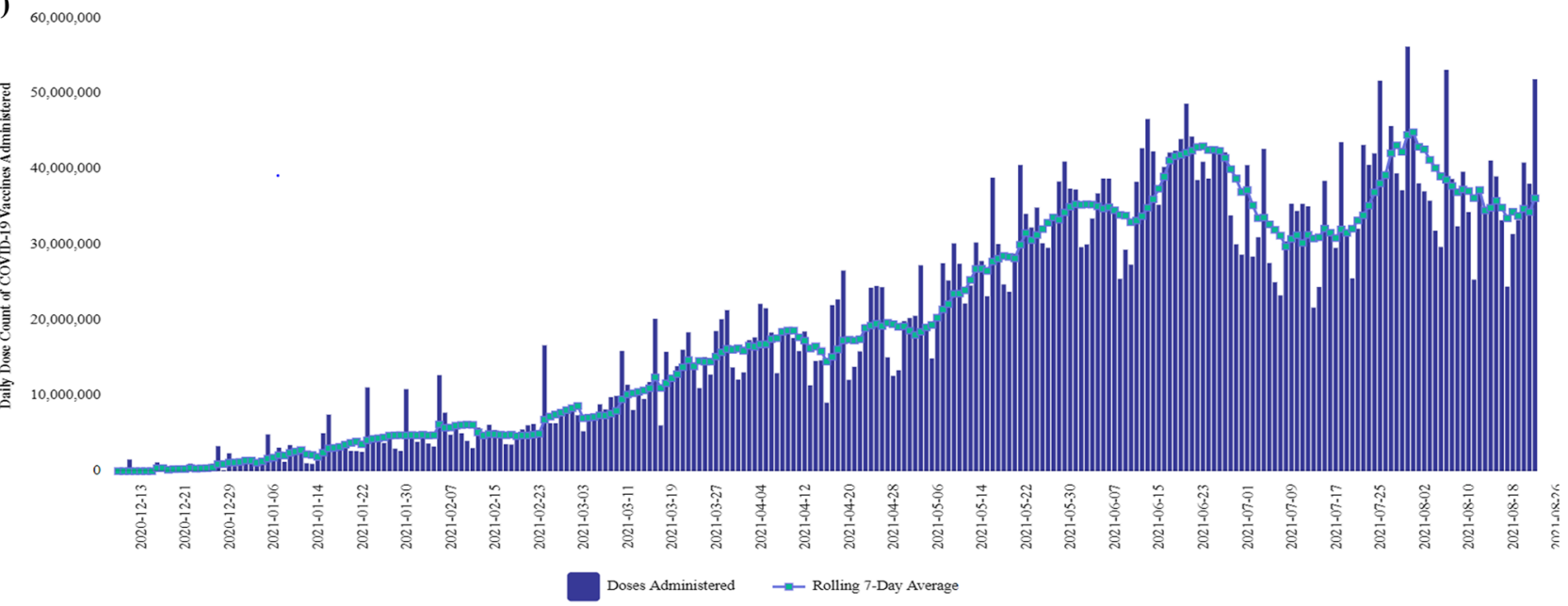

Fig. 8 a Cumulative COVID-19 vaccine doses administered per 100 peoples in different countries and b weekly global rise in cumulative vaccination rate since January 2021 (Source: Pharmaceutical technology 2021)

plastic-based masks and gloves resulted in a cumulative increase of plastic debris in the aquatic environment and is potentially carried by the wind, stormwater, wastewater, and drainage systems (Eriksen et al. 2013). Reportedly, $\sim 8-13 \times$ $10^{6}$ tonnes of plastic trash is directly or indirectly disposed of in the water bodies every year (Guern 2019). The inappropriate disposal of PPE does intensify the problem. Gary Stokes (the creator and director of the Ocean Asia NGO) and his team are currently working on the management of ocean surface trash (Chow et al. 2020), according to whom, the used masks and gloves have been seen all along the seashore and high tide line with a cumulative deposition of the new deposits with each current. Reportedly, $\sim 5.25$ trillion plastic pieces with $3 \%$ of global plastic waste are floating on the surface of the ocean (Eriksen et al. 2014). Mostly, this debris is mistakenly consumed by many seabirds and animals, which tend to block their gastrointestinal tract, and may even lead to death. For instance, the potential cause of death of a Magellanic Penguin (Spheniscus magellanicus) in Brazil on 9th September 2020, was reported to be the inappropriate consumption of black face masks (Ewbank et al. 2020). As stated by the Intergovernmental Platform for Science Policy on Biodiversity and Ecosystem Services (IPBES), aquatic plastic pollution has enhanced by 10 -fold since 1980 and affects at least $\sim 267$ species, including $\sim 44 \%$ of seabirds, $\sim 43 \%$ of marine mammals, and $\sim 86 \%$ of marine turtles, and may even indirectly affect human beings via food chains (Ferrier et al. 2019). Similarly, in December 2018, at the Waka Tobi National Park in Indonesia, a sperm whale was found dead with $\sim 25$ bags, $\sim 115$ cups, two slippers, and four bottles in its stomach. More than $\sim 1000$ plastic pieces with an overall weight of $\sim 6 \mathrm{~kg}$, was estimated to be trapped (Jensen and Schuettler 2018).

With time, the plastics can also break into small pieces, i.e., microplastics $(<5 \mathrm{~mm})$ under environmental conditions (like UV radiation, wind velocity, sunlight). Such micro/nanopolymeric particles, directly and/or indirectly, are consumed by living organisms and thus are a subject of immense concern for global food safety (Hebner and Maurer-Jones 2020). Currently, plastic-based PPE like face masks and gloves is the major source of microplastic fibers in the environment. For instance, most of the safeguard PPEs such as Tyvek for protective suits, N95 masks, gloves, and protective face shields are made of PP and thus may release dioxin and other toxic elements and may even remain in the environment for a longer duration (WHO 2020f). Plastic waste may also 
contribute to the emission of carbon which significantly affects global food and climate change (North and Halden 2013). Moreover, the urban plastic waste not only triggers pollution levels but may also escalate the risk of urban flooding, thereby activating numerous zoonotic and biological vector-borne diseases (for example, the vector for dengue and Zika is the mosquito Aedes spp.) (Lindsay et al. 2017).

The inappropriately disposed of plastic waste may also contaminate the soil and groundwater. The leachate generated by waste decomposition contains a large number of substances that are likely to pollute groundwater. The cumulative impacts of such medical wastes on health care workers are farreaching. Furthermore, the infectious waste is not only disposed from the hospitals and healthcare centers but also produced from households, as the virus-laden waste can also be generated by infected people with minor or negligible symptoms during their home isolation period. The handling of contaminated plastics waste is also a potential mode of virus transmission. Therefore, people involved in waste management (cleansers, trash collectors) are at a higher risk zone due to their repeated contact with infected waste. Such circumstances are extremely critical in developing countries where the rag pickers and informal waste collectors are mostly improperly equipped with PPEs.

\section{Additional challenges associated with disposal practices and plastic waste treatment during the pandemic}

Landfilling, incineration, and mechanical recycling are the most commonly used waste disposal techniques worldwide. Globally, between 1950 and 2015, only 9\% (600 Mt) of total produced plastic $(6300 \mathrm{Mt})$ was mechanically recycled, $12 \%$ $(880 \mathrm{Mt})$ was incinerated, and 60\% (4900 Mt) of plastic wastes were disposed of and accumulated in landfills or the natural environment due to mismanagement (Geyer et al. 2017). However, these traditionally used techniques are inefficient for waste disposal and treatment due to an unprecedented increase in waste generation. Table 3 illustrates the various advantages, disadvantages, and challenges in landfilling, incineration, and mechanical recycling during the COVID-19 pandemic.

In the waste management hierarchy, landfilling is the least preferred option as it consumes scarce, valuable land and squanders limited resources. However, it is still adopted by numerous places around the world, especially in developing countries. Moreover, the increased plastic waste generation and inefficient waste management systems lead to unscientific landfilling and indiscriminate dumping worldwide. The prioritization of landfilling may induce improper littering and open burning of a significant amount of plastic waste, which could lead to an increase in the ecological footprint. In many Indian cities, significantly increased cases of unscientific landfills and open burning of plastic waste were reported during the pandemic (Corburn et al. 2020; Shooshtarian et al. 2020b). Furthermore, a significant reduction in the recycling activities and depletion of incineration capacity in most of the countries during the outbreak indicates the eventual leakage and mishandling of a remarkable amount of plastic waste in landfills, which creates a long-term impact on the environment. Based on pre-pandemic trends, it is estimated that $12,000 \times$ $10^{6}$ metric tonnes of plastic-based waste will be dumped in landfills by 2050 (Geyer et al. 2017). Zhao et al. in their study also discussed the efficacy of co-incineration in the management and effective disposal of medical waste (Zhao et al. 2021). The current upsurge in demand leading to plastic waste generation will further worsen the situation and pollute our water and land with a drastic increase of SUP fibers and other disposable plastic products.

Table 3 Advantages, disadvantages, and challenges in landfilling, incineration, and mechanical recycling

\begin{tabular}{|c|c|c|c|}
\hline $\begin{array}{l}\text { Waste } \\
\text { treatment } \\
\text { method }\end{array}$ & Advantages & Disadvantages & Challenges during COVID-19 scenario \\
\hline Incineration & $\begin{array}{l}\text { Relatively mature technology for } \\
\text { recovery of energy } \\
\text { Disinfection and sterilization is not } \\
\text { required } \\
\text { Due to the high calorific value of } \\
\text { biomedical waste, less fuel is required } \\
\text { Low sensitivity to waste composition }\end{array}$ & $\begin{array}{l}\text { Release of hazardous and toxic gases such } \\
\text { as furans and dioxins } \\
\text { Only heat is recovered }\end{array}$ & $\begin{array}{l}\text { Development of Flue gas treatment technology } \\
\text { Introducing carbon capture and storage } \\
\text { technology into the incinerator }\end{array}$ \\
\hline Landfilling & $\begin{array}{l}\text { Simple operation } \\
\text { Less input and transportation cost }\end{array}$ & $\begin{array}{l}\text { Difficult decomposition } \\
\text { Waste of land resources }\end{array}$ & $\begin{array}{l}\text { Development of the new approaches for safe } \\
\text { and sterile landfilling }\end{array}$ \\
\hline $\begin{array}{r}\text { Mechanical } \\
\text { recycling }\end{array}$ & $\begin{array}{l}\text { Simple operation } \\
\text { Less pollutant produced }\end{array}$ & $\begin{array}{l}\text { Widespread use of filler, additives, and } \\
\text { masterbatches make recycling difficult }\end{array}$ & $\begin{array}{l}\text { Automation in recycling activities } \\
\text { Introduction of new approaches to recycling } \\
\text { the multi-layer film and blister packaging } \\
\text { Recycling of mixed plastic waste }\end{array}$ \\
\hline
\end{tabular}


Incineration as a thermochemical treatment is another waste management practice, where waste materials are combusted at high temperatures to reduce the volume. Incineration of mixed plastic waste, irrespective of impurities and sorting, in the temperature range of $\sim 800-1000{ }^{\circ} \mathrm{C}$ for safer disposal by providing waste heat recovery may be a wiser choice, considering its lower labor requirement with less risk of contamination (White 2020; Klemeš et al. 2020). The main challenge is that COVID-19 creates a wave of waste that breaches the existing incineration capacity, thus exceeding the processing capacity by a larger margin. For instance, the maximum production of medical waste of $\sim 240$ tonnes per day in Wuhan, China, exceeded the existing incineration capacity of $\sim 49$ tonnes per day during the coronavirus pandemic (Silva et al. 2021). Furthermore, incineration is being prioritized over recycling and landfilling to handle the municipal and medical solid waste, which in turn would affect the quality of air in a medium- to long-term scenario. The greenhouse gases (GHG), like $\mathrm{CH}_{4}$ and $\mathrm{CO}_{2}$, are usually released in significant quantities during the burning of plastics waste or the decomposition of plastic waste in landfills. For example, in the UK, municipal solid waste incineration has a carbon footprint of $0.179 \mathrm{CO}_{2}$ equivalent/ton municipal solid waste while that from landfilling is $0.395 \mathrm{CO}_{2}$ equivalent/ton municipal solid waste (Jeswani et al. 2012). Thus, the release of hazardous and toxic gases such as furans and dioxins from the incinerators without purification remains a subject of concern that should also be addressed.

Due to the unprecedented increase in waste products as well as hygiene concerns of workers, global plastics recycling declined alarmingly during the pandemic. For instance, many cities in the USA have ceased recycling programs due to concerns about the risk of COVID-19 spreading in the recycling center (Zambrano-Monserrate et al. 2020). Similarly, Singapore has also reduced the frequency of household recyclable waste collection during the circuit breaker period (NEA 2019). Additionally, the low collection efficiency, restricted transportation, unavailability of the market for recycled plastics, and the unorganized recycling sector in developing countries, have affected the organized disposal of plastic waste (Sharma et al. 2020). For instance, among developing countries like India, Kenya, and Brazil with relatively low economic growth, the adequate facilities management of MSW is not well established (Amaral et al. 2020). Therefore, the main challenge is to implement appropriate waste management strategies during and after the COVID-19 pandemic that ensures the continuity in the waste disposal and recycling services along with the safety of service workers for regulated and safe collection, disposal, and treatment of medical waste. Furthermore, the main constraint in the mechanical recycling of waste plastic is the presence of additives and inorganic/ nonpolymeric impurities, polymeric cross-contamination, improper separation of waste at source or during collection, and partial polymer degradation (Hopewell et al. 2009). Currently, mechanical recycling facilities are feasible for a small portion of plastics, mainly PET beverage bottles and more rigid containers made of HDPE like milk jugs, but not suitable for the multiplex stream of films, sachets, bags, synthetic fibers, or multilayer containers (Hopewell et al. 2009). Thus, it is challenging in the recycling sector to optimize the use of different resources for improving efficiency and productivity by reducing the quantity of waste produced.

\section{Adopted recommendations}

The perils of plastic pollution have mobilized business corporations, governments, and communities around the world to fight against its spread in the environment (Schnurr et al. 2018). In the recent past, there have been communal, technological, and institutional amendments like the progressive reduction of SUPs in various nations, decisions by commercial organizations and companies to lessen the plastic footprint, activities by non-profit organizations to tidy up seashores and sea, and changes in public behavior to minimize the plastic usage and waste generation has raised desire for positive developments (Heidbreder et al. 2019; Xanthos and Walker 2017). In 2017, the united nation also declared plastic pollution as a worldwide crisis which encouraged numerous business establishments to adjust their corporate strategies in order to accelerate the transition to a circular economy (UNEP 2017).

The management of plastic waste around the world has already been insufficient, considering the generation of waste in the pre-pandemic situation. The SUPs present a substantial threat to environmental sustainability, as discussed in the previous section. Moreover, waste management infrastructures are typically designed to operate reliably with average productivity and moderately varying waste composition under normal conditions. But the histrionic change in the dynamics of waste composition and production caused by the pandemic far exceeds current waste management infrastructure and thus disrupts normal operations. Therefore, it is necessary to move away from the traditional linear recycling model and radically reconsider the production, design, use, and reuse of plastics to avoid their conversion into waste. Nowadays, plastic engineers are more focused on the designing and development of ecologically safe, biodegradable, and antimicrobial materials (Moustafa et al. 2019) (Das et al. 2021). Moreover, the research and development of low-cost new-age packaging materials, vis-a-vis risk assessment, and long-term implication of the extensive use of these PPEs, present a potential window to explore in the near future. The general representative practices followed for plastic waste management during the COVID-19 pandemic are illustrated in Fig. 9. However, the present surge in demand for packaging material indicated the need to adopt 


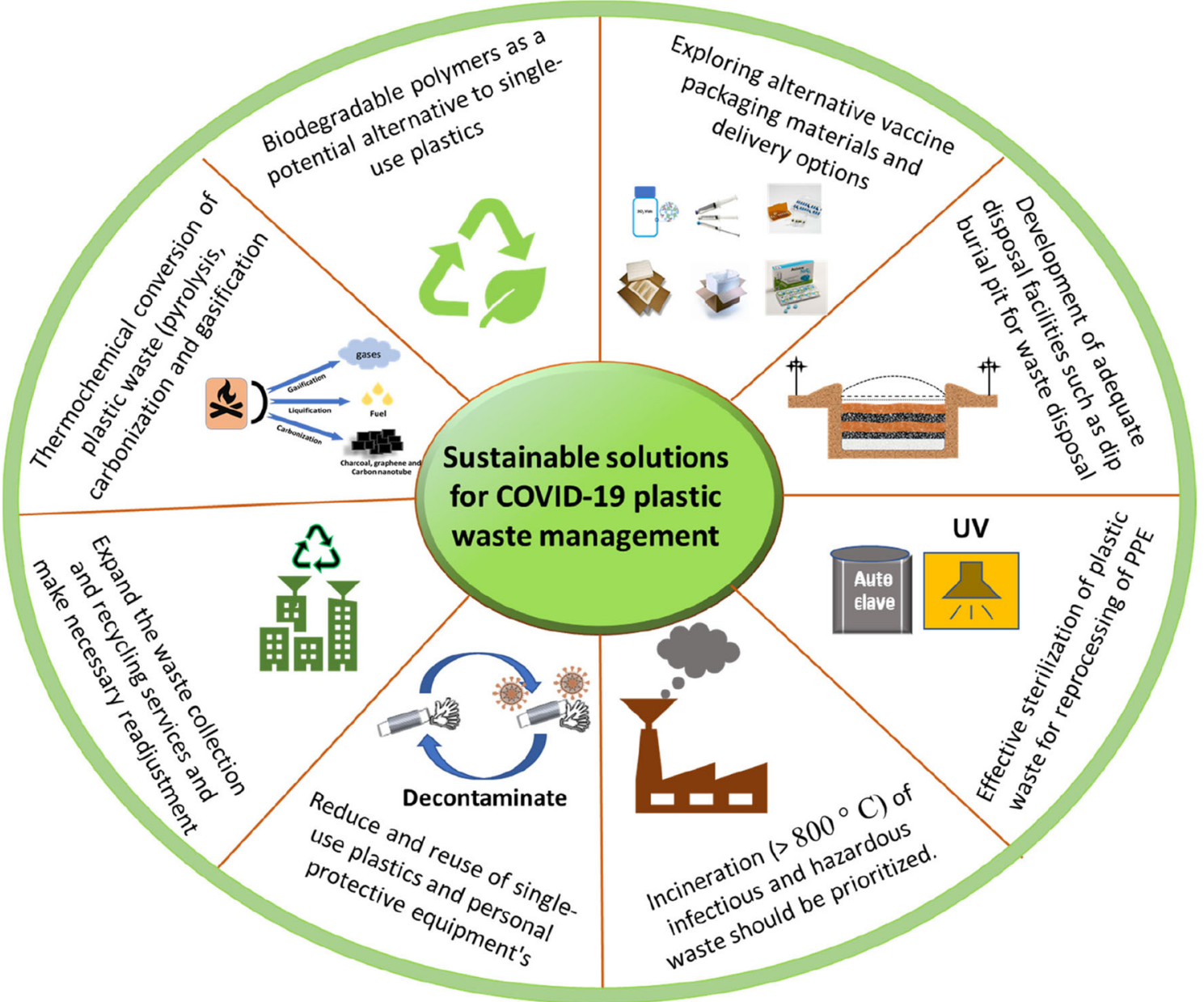

Fig. 9 Sustainable COVID-19 plastic waste management practices in waste management during the COVID-19 pandemic

a radical approach for the vigilant and safe disposal of contaminated plastic waste, highlighting the risk of exposure. Currently, there are no unified international rules and regulations for the management of non-biodegradable plastic waste products, but some countries have already started putting strict measures to mitigate the proliferation of polymer plasticbased waste.

\section{Optimizing new challenges and strategies for effective COVID-19 waste management}

The unification of new approaches and technological solutions for the collection, sorting, along with secondary treatment, including sterilization of PPE kits, could be a favorable option to address the crucial challenges during and postpandemic vaccination drive period. The rising demand for PPE, sanitary products, and other sterilization products by healthcare workers and/or the general public and their improper disposal may lead to the generation of more infectious and hazardous waste, and thus should be stored in properly labeled double-lined sealed bags. Moreover, the amount of noninfectious waste $(\geq 80 \%$ of the total healthcare waste generation) needs to be segregated, collected, and disposed of as municipal waste (Sahiledengle 2019). Furthermore, the food waste and the packaging materials discarded after being used by COVID-19 positive patients also contribute to the spread of disease and thus should be handled with caution. Therefore, such infectious waste can be wrapped in paper wraps for at least $24 \mathrm{~h}$ (van Doremalen et al. 2020), as the persistence of the virus on the paper surface is $<24 \mathrm{~h}$, and then, should be buried in double-layer compostable, biodegradable bags. In order to match the requirement, the frequency of collection should be increased as well as a special provision should also be provided for the collection of infectious waste from quarantine homes. Practicing proper segregation at home and following updated waste disposal strategies tend to minimize the recycling workload, the number of local assistants, and the extent of regional support. Concurrently, it becomes an individual's duty and partly a social responsibility to follow simple guidelines and regulations while discarding used face masks and other medical wastes. In an endeavor to resume MSW management services, some of the developed countries have prioritized the strategy of waste categorization prior to collection and processing. For example, the UK has 
categorized recyclable waste in medium and low priority belts and is supposed to be collected once in one or two weeks (DEFRA 2020).

Integrating machine learning and robotics for segregating and further processing of recyclable materials tends to improve the recyclability rates and provide qualitative products. Sinha et al. developed a proficient method for the selection of the recycling container based on the waste discarded by the user. The authors introduced an Ontology Web Language (OWL)-based model to ensure the smart sorting of plastic waste products to enhance their recyclability. The model also provides information about the amount of valuable recyclable materials present in mixed waste (Sinha and Couderc 2012). In addition, $\mathrm{Chu}$ et al. suggested a multilayer hybrid deeplearning system (MHS) to automatically segregate waste that is disposed of in the urban public area (Chu et al. 2018). Thus, the use of automated waste treatment technologies (AWTT) with minimum operator involvement should be prioritized during the pandemic. Moreover, according to Dente and Hashimoto (2020), "the combination of analytical tools such as LCA, network analysis, input-output analysis, and material flow analysis seems imperative to thoroughly understand the consequences of the COVID19 epidemics." Therefore, the need to implement best management practices for waste handling and to maintain hygiene should be re-emphasized to limit the exposure of workers to likely contaminated waste.

\section{Techniques adopted for disinfection of plastic waste}

Recognizing and investigating outbreaks of infections in both community and healthcare professions by practicing appropriate preventive measures such as stringent sanitation and hygienic conditions are the main principles to combat the present situation. Therefore, there is a need to sterilize general hospital waste and used PPEs prior to disposal and further treatment. Additionally, prior to waste disposal, the general public should decontaminate the waste with disinfectants, such as alcohol, hydrogen peroxide, and chlorine, to reduce the risk of transmission of infection among rag pickers and sanitation workers. According to the WHO recommendation, two disinfection formulations, namely $\sim 75 \%$ 2-propanol or $\sim 80 \%$ ethanol, are suitable to minimize viral outbreaks (Kratzel 2020). Chemical disinfectants like calcium hypochlorite, sodium peroxide, sodium hypochlorite, bleach, chlorine dioxide, etc., can be considered the most feasible options due to their properties like colorless, tasteless, non-corrosiveness, odorless, and ease in water-solubility, with no possible hazardous by-product generation after the treatment (Al-Sayah 2020). Other disinfectant technologies (physical and chemical methods of disinfection) such as UV, ozone, or bioengineering approaches, scientific routes for sterilization of infected biomedical waste (BMW), such as via radio wave/microwave disinfection and autoclaving/steam sterilization, can offer a sustainable strategy to treat such plastic waste (Mohapatra 2017; CU-Boulder 2008). Reportedly, vaporous hydrogen peroxide (VHP), ethylene oxide, and ultraviolet germicidal irradiation (UVGI) can effectively sterilize the used PPEs and medical safety kits (Saini et al. 2020). Further, mechanical crushing of used PPE into smaller fractions followed by chemical disinfection has been reported to be efficient in inactivating infectious microbes. Reportedly, microwave/ radio wave disinfection is an energy-efficient technology and is relatively faster, thereby producing high yield with minimal environmental consequences as it does not release any toxic particles or residue upon sterilization. It is also known that an on-site treatment method, which includes an autoclave equipped with high thermal energy $(\sim 93$ to $\sim 177$ ${ }^{\circ} \mathrm{C}$ ) and saturated water vapor, effectively disinfects plastic medical waste (Saini et al. 2020). This is attributed to the latent heat possessed by the steam generated that causes denaturation and coagulation of microorganisms which may lead to their inactivation without any significant release of harmful/toxic gases in the surrounding atmosphere. Most of these methods utilize disinfection equipment and disinfectants, which are readily available in hospitals or clinical centers and can be considered for handling and sterilizing used facemasks and PPE. All in all, these sterilization methods might be helpful in providing better options for reuse and recycling of some commonly used plastic-based protective gears like surgical masks, face shields, respirators, and N95 gloves in developed and developing countries, thereby reducing the transmission rate as well as minimizing the plastic waste generation during this still ongoing and periodically fluctuating intensity of pandemic.

In addition, an appropriate disinfection technology should be chosen based on the amount and composition of the waste, the associated costs, and the maintenance required. In the case of a large amount of infectious waste from the health sector ( $>10$ tonnes/day), incineration remains the best option, as pathogens cannot tolerate high temperatures $(>800$ ${ }^{\circ} \mathrm{C}$ ). If the amount of medical waste is low ( $<10$ tonnes/ day), chemical (e.g., using chemical disinfectants) or physical (high-temperature steam sterilization or microwave oven) disinfection methods may be used (WHO 1999).

\section{Reduction/reuse of SUPs and PPE}

During the COVID-19 pandemic, both the regional supply and demand chain balance of PPEs is adversely disrupted and this sudden surplus in demand could not be satisfied by the limited indigenous manufacturing potential though many nations have now ensured its plenty assisted by global collaborative efforts. In developed countries like the USA, there was a vast gap in the supply of PPE, as health professionals were demanding PPE like never before at one point in time at the 
Fig. 10 Construction of a pit for onsite burial during COVID-19 pandemic
Cemented or sheet of wire mesh embedded in top fill

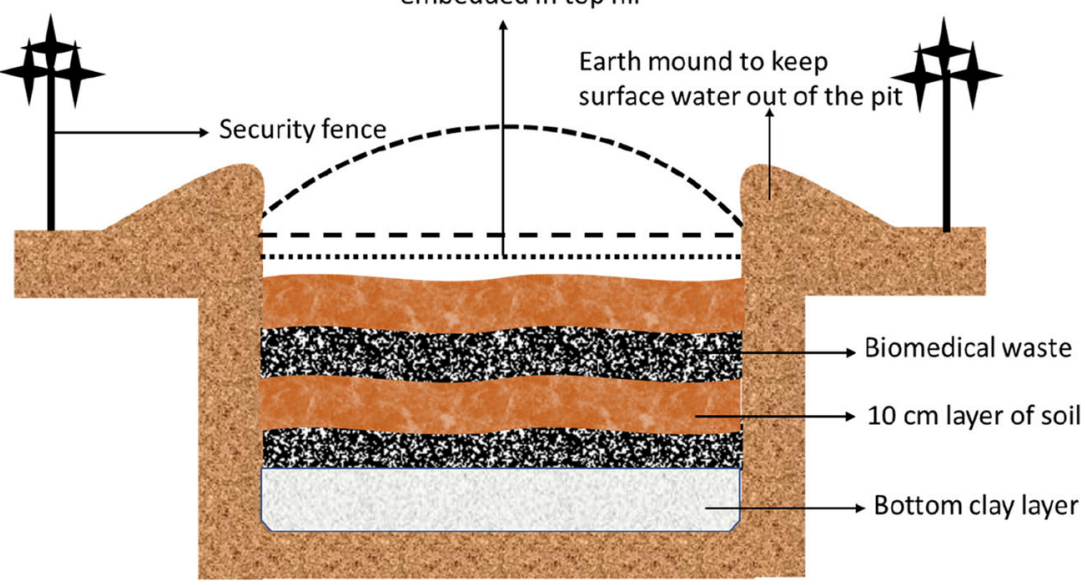

beginning of the outbreak. Concerns pertaining to such unprecedented use of PPE induced SUP generation has altered climate and ecological experts raising flags of potential environmental consequences. Therefore, the focus on the reuse of PPE equipment by facilitating radically new approaches becomes the need of the hour.

Additionally, to reduce the PPE storage, PPE can be reused after proper disinfection. Moreover, the quality of PPE should not be compromised, such that it offers, high potential for disinfection and reuse. This rational use and reuse of materials could lead to a significant reduction in the production of medical plastic waste. Jessop et al. reported that reusable PPE is not only energy-efficient, eco-friendly, and economically viable, but also can reduce the amount of solid waste by $93 \%$ and usage of natural resources by $28 \%$ (Jessop et al. 2020). For instance, a group of the All India Institute of Medical Sciences (AIIMS) working on the COVID-19 pandemic has developed a customized PPE equipped with the face shield, N95 facemask, goggles, hand gloves, protective gowns, and shoe covers. These types of PPE are manufactured from water-proof warp and weft fabrics made of polyester with the entire interior coverall. It is reported that this customized PPE is reusable, user-friendly, and cost-effective (US\$11.00) due to the sufficient availability of the materials used (Sureka et al. 2020).

Reportedly, material scientists, health experts, and analytical ecologists are working towards finding the most effective method for disinfecting used FFP respirators. Some potential chemical and physical methods for disinfection advocate the use of chemicals like chlorine dioxide, ethylene oxide, hydrogen peroxide, alcohol, bleach, ozone decontamination, soap solutions, etc., while another approach advocates the use of heat with dry air or stream, gamma irradiation, microwave, UV rays, etc. (Rubio-Romero et al. 2020; Kchaou et al. 2020).

\section{Innovative solutions for adequate waste disposal}

With the restricted choices and burden on the existing waste management infrastructures, it is very challenging to control excessive plastic pollution. Therefore, the integration of new approaches and technology-assisted mitigation strategies could be beneficial in addressing the key challenges during and in the aftermath of the pandemic scenario.

A significant decline in recycling activities and the depletion of existing incineration capacities in many developing/ low-income countries during the pandemic may promote deep burial of infectious waste in a safe and secured landfill (UNEP 2020), an example of which is shown for representation in Fig. 10. Additionally, sites where in situ or centralized decontamination facilities are lacking should also use this radically new approach of landfilling. In this method, collected infectious waste can be buried in a close pit that is sealed to the bottom of the existing landfill with clay or a geosynthetic. Briefly, once the waste has been deposited in the pit, the daily cover should be filled with fresh soil and/or a mixture of soil and lime. The top thin layer of the pit should be cemented and/or embedded with a concrete wire mesh cover, followed by $\sim 50 \mathrm{~cm}$ of soil cover. The pit areas should be sealed with metal wire fencing and should be kept away from humans or animals. Thus, the burial technique can be employed during disaster emergency conditions such as COVID-19 for the safe and secure disposal of infectious waste.

Depending on the volume of waste, incineration is an ideal alternative for processing waste $>10$ tonnes/day, while other thermal techniques such as autoclave, microwave radiation are preferred for the production of waste with a total yield of less than 10 per day (Silva et al. 2021). Furthermore, after an appropriate decontamination cycle by steam sterilization, the residues of biomedical waste can be safely treated according 
to the regulations for solid non-hazardous waste (Silva et al. 2021). According to the WHO guidelines, mandatory incineration of infectious plastic waste, including used PPE, masks, and gloves, should take place in the temperature range of 900 to $1200{ }^{\circ} \mathrm{C}$ (WHO 2020d). In Germany, to ensure safe waste disposal, the incineration process follows a strict procedure and is carried out at $\sim 1000{ }^{\circ} \mathrm{C}$ (ACR+ 2020). In addition to improving the capacity of the existing incinerators, new approaches and technological solutions are needed to cope with the growing production of plastic waste. In Spain, cement plants are allowed to co-incinerate plastic waste if required (ACR+ 2020). Furthermore, the design capability of the incinerators requires a complete overhaul to deal with the soaring production of plastic waste and the compositional dynamics caused by pandemics. In order to alleviate the toxic gas emission, modern incinerators act as pollution mitigation equipment using fabric filters (often with Teflon membranes) to improve the collection of microplastics that may encapsulate the dioxins present in/on the solid particles (Vejerano et al. 2014). Numerous developed countries, such as Denmark, Poland, and Sweden, have embraced advanced air pollution controlling incineration technologies for treating waste (Malinauskaite et al. 2017).

In order to mitigate the challenges posed by the excessive use of SUP in the present scenario, many industries are currently focused on developing new business models for the collection and vigilant disposal of contaminated nondegradable plastic waste. Such models are the critical bottlenecks to the economics of mechanical recycling and are a potential source of exposure to contamination as well. Thus, initiatives should be implemented at the local level to reconstruct the trust in the safety of sorted/segregated waste and develop clean, homogenous plastic streams for recyclers. In addition, novel systematic technologies need to be formulated in order to recycle mixed plastics waste and other complex forms of plastic waste at a large scale. In order to obtain higher recyclability rates and qualitative products, integrated machine learning should be executed in the sorting and processing of recyclable plastics. Detailed strategies should be planned and implemented for the safe disposal of fancier and multi-layer plastic packaging, which are complex and economically not feasible to be recycled. According to the International Solid Waste Association (ISWA), PPEs such as masks, gloves, and fabric, as well as contaminated residues, are not recyclable (Scheinberg et al. 2020). Thus, packaging companies should contemporize novel product designs with recyclable efficacies before launching them to the market (Dente and Hashimoto 2020). Moreover, very limited research has been reported for the recycling technologies for nonwoven textiles, from which most PPEs are made (Karim et al. 2020). It is urgent that efforts in this direction to pull technology development for recycling of non-woven textiles must be taken up aggressively, considering the fact that PPEs may be an integral asset to counter any future biological and medical emergency that mankind may confront unexpectedly. The zero-waste approach would be a radically sustainable solution that enables the members of the European Union to recycle plastic waste between $\sim 70$ and $80 \%$ while declining greenhouse gases (GHG) emissions from disposed of toxic wastes and incineration set-ups (Zero Waste Europe 2020). The zero-waste approach encompasses "the conservation of all resources by means of responsible production, consumption, reuse and recovery of products, packaging, and materials without burning, and with no discharges to land, water or air that threaten the environment or human" (ZWIA Planning Group 2004; Sarkodie and Owusu 2020). In 2019, the Singapore government developed the most awaited zero-waste master plan to address the waste management problem and to develop a sustainable, resource-efficient, and climate-resilient nation. This plan mainly aims to extend the lifespan of Semakau landfill beyond 2035, to reduce the amount of waste disposed of in landfills per capita/day by $\sim 30 \%$ by 2030 , and to reach at least $\sim 70 \%$ overall recycling rate by enhancing the non-domestic recycling rate from $\sim 74 \%$ in 2018 to $81 \%$ by 2030 and domestic recycling rate from $\sim 22 \%$ in 2018 to $\sim 30 \%$ by 2030 (MEWR, NEA 2019).

\section{Thermochemical conversion of COVID-19-related plastic wastes}

There is an emerging need to step away from the conventional incineration and landfilling models and to fundamentally rethink the potential of modern technologies in addressing the rising global plastic disposal concern. Therefore, the conversion of the plastics value chain into value-added products (like gases, biofuel, and carbon-based materials) is the best solution for sound waste management which not only needs to be prioritized but also be incorporated among international agreements for the management of the accumulated plastic waste (Saha et al. 2019). Reportedly, thermal conversion technologies facilitate a volume reduction of up to 80-95\% (Kumar and Samadder 2017). Ferronato et al. estimated the waste to energy conversion technologies implemented in both developed and developing nations. According to the survey, most of the developed countries have switched from landfills to wasteto-energy technologies for waste management, either due to the unavailability of land area or environmental concerns (Ferronato and Torretta 2019). Chemical treatment consists of various processes like glycolysis, amino-lysis, hydrogenation, pyrolysis, hydrolysis, and gasification. These processes are considered prospective ways of conversion of plastic waste into value-added products. 


\section{Pyrolysis}

Nowadays, pyrolysis is one of the most frequently used developed waste conversion techniques as this process easily converts the non-recyclable plastic waste into artificial crude oil and value-added petroleum-based products like naphtha, fuel oil, and diesel. Pyrolysis majorly decomposes large macromolecular polymer molecules into smaller simpler molecules, in the absence of oxygen/air at high pressure and temperature, with/without the presence of a catalyst. Although the current waste management system depends on incineration and landfilling, in the future, pyrolysis offers an effective means for addressing the waste management problem. The mechanism and products of pyrolysis usually vary for different types of plastics. Such a thermochemical plastic waste treatment technique is not only a promising alternative to address the plastic pollution and dumping problems but also helps in recovering valuable energy and products such as solid, oil, and gas. The waste conversion processes to solid (carbonization) and gaseous (gasification) products are discussed in the subsequent sections. The ability of pyrolysis to produce a large number of liquid products at a wide range of temperatures and the ease of optimizing process parameters to obtain the products with specific properties enhances its efficiency to volatile polymeric waste. Moreover, pyrolysis is an environment friendly process as it emits very low carbon due to its lower carbon monoxide $(\sim 0.8-3.9 \mathrm{v} / \mathrm{v} \%)$ and carbon dioxide $(\sim 1.0-9.1 \mathrm{v} / \mathrm{v} \%)$ generation tendency when compared to other combustion processes (Jaski 1973). According to a study, investment in the pyrolysis process for a waste management system could even result in an internal return rate of $\sim 43 \%$, thereby attributing to its economic feasibility (Jaski 1973). Pyrolysis does not require any preprocessing requirements, such as segregation/separation of different types of dissimilar waste plastics. Pyrolysis-based conversion of PP-type plastic, which is mostly used in PPEs, into biofuel can help to overcome the sustainability challenge. For instance, pyrolysis of PP usually occurs at high temperatures $(573-773 \mathrm{~K})$ in the absence of oxygen to facilitate thermal cracking of macromolecules in the form of liquid, char, and gas (Dwivedi et al. 2019). Many researchers utilize pyrolysis for treating plastic waste due to its ability to produces a large quantity of liquid oil, i.e., up to $\sim 80 \mathrm{wt} . \%$, at temperatures $\sim 773 \mathrm{~K}$ (Abnisa and Wan Daud 2014).

Budsaereechai et al. reported the catalytic pyrolysis of waste plastics such as PP with economical binder-free pelletized bentonite clay. The process yielded pyrolysis oils which can be used as drop-in replacements for commercial liquid fuels such as diesel and gasohol (Budsaereechai et al. 2019). Pyrolysis of PP conducted at $\sim 1013 \mathrm{~K}$ by the Demirbas team yielded $\sim 49.6 \mathrm{wt} . \%$ gas, $\sim 48.8 \mathrm{wt} . \%$ liquid, and $\sim 1.6 \mathrm{wt} . \%$ residues (Demirbas 2004). Reportedly, the larger content of hydrogen and carbon and the absence of oxygen in the resulting pyrolytic fuel lessens the need for further up-gradation, unlike biofuels. Further, the resulting fuel has a high calorific value due to the absence of water. More so, the absence of oxygen also makes the fuel non-acidic and non-corrosive, unlike biofuel.

In the pyrolysis of plastics such as polystyrene (PS), high yields (> $95 \mathrm{wt} . \%$ ) of liquid products can be obtained. Onwudili et al. estimated a resulting pyrolytic oil yield of 97 wt.\% when hydrolysis was performed at $\sim 425{ }^{\circ} \mathrm{C}$ (Onwudili et al. 2009). The possibility of treating PE, PP, and PS using pyrolysis elucidates its feasibility in treating some components of PPEs, such as disposable face masks and hand sanitation containers. Meanwhile, current research focused on pyrolysis of PET and PVC, even though they were not easily pyrolyzed like PE, PP, and PS. Currently, pyrolysis of PET provides a low liquid product yield, which is even lower than the gas product yield. Fakhrhoseini and Dastanian obtained a low yield for the liquid product $(\sim 40$ wt.\%) than for the gas product ( $52 \mathrm{wt} . \%)$ on pyrolysis of PET. Similar to PET, pyrolysis of PVC has also not been extensively studied (FakhrHoseini and Dastanian 2013). PVC contains $\sim 57$ wt.\% of chlorine thus may lead to the production of hydrochloric acid or chlorine gas. Pyrolysis of PVC also produced low liquid product yield, i.e., $<15 \mathrm{wt} \%$ (Miranda et al. 2001). Thus, pyrolysis may not be feasible to treat safety goggles and some components of hand sanitation containers that are often manufactured using PET and PVC.

\section{Carbonization}

Nowadays, carbonization is a promising approach for the utilization of waste plastics. The process involves the conversion of polymer precursors into value-added carbon materials like graphite carbon (carbon nanofibers, graphene, etc.) and amorphous carbon (porous carbon, activated carbon, etc.) at high temperatures. The thermal treatment can be varied with reaction conditions (pressure, catalyst, and oxygen content). Thus, carbonization provides excellent resource recovery as well as environmental protection and is suitable for most plastics as the pre-treatment process is very simple, and the carbonized products are valuable and tailorable. Rago et al. performed carbonization of mixed solid wastes with LDPE at $\sim 300{ }^{\circ} \mathrm{C}$ for $\sim 30 \mathrm{~min}$, which resulted in higher char yield and energy content (Rago et al. 2020). Similarly, Hanoglu et al. investigated the carbonization of textile fibers with PEs and acrylic at $\sim 300-400{ }^{\circ} \mathrm{C}$ and reported the role of temperature in defining the solid product (Hanoğlu et al. 2019). In addition, the carbonization could also produce solid product (char) having high-energy-density $(\sim 18-25 \mathrm{MJ} / \mathrm{kg})$ but low ash and sulfur content $(<10 \mathrm{wt} . \%)$. Recently, the hydrothermal carbonization treatment of waste has attracted great attention as it is considered to be more facile and greener as compared to other conventional decomposition methods. Earlier, the technique 
was mainly used for bio-based products. But, now, plastics like PP, PVC are being processed through the microwaveassisted hydrothermal carbonization process (Poerschmann et al. 2015; Adolfsson et al. 2018). Advanced recovery of resources (like carbon nanotubes, graphene) from plastic waste appears to be an effective solution to solving the current dilemma of global plastic waste disposal (Yao et al. 2018). However, research related to carbon recovery and large-scale plastic waste carbonization still requires significant contributions.

\section{Gasification}

Gasification is a process in which carbon-containing materials are converted into a mixture of hydrogen, carbon dioxide, methane, carbon monoxide, and a larger chain of hydrocarbon gases by heating the materials at a very high temperature $\left(500-1300{ }^{\circ} \mathrm{C}\right)$ in a controlled atmosphere. The catalyst can be used to reduce energy and control the efficiency of the product. On the basis of their composition, the gasification products are used as fuel or chemical feedstock (syngas). Syngas can also be used to make many fuel cell products and fuels used to generate electricity (Saebea et al. 2020). Sansaniwal et al. discussed that the desire to generate energy, fuels, and chemicals from syngas makes gasification an attractive option for the revitalization of plastic waste (Sansaniwal et al. 2017). In addition, gasification has the advantage in the flexibility of the raw material, in which different types of plastics can be used, including a mixture of plastics and a mixture of plastics with other materials, without drastically changing the products (Lopez et al. 2018). Although there has been recent interest in plastic gasification, the technology for the gassing of other raw materials such as carbon has already emerged; thus, the knowledge gained by gasification of other raw materials can be applied in the gasification of plastics. These benefits make it a more attractive choice than the pyrolysis process. Nevertheless, the disadvantage of gasification, especially of plastics, is the high tar content in the gaseous products, which can reach $160 \mathrm{~g} / \mathrm{Nm}^{3}$ (Mastellone et al. 2010). However, this disadvantage can be overcomed by developing a gas purification system after production or before the use of gas-based products (Anis and Zainal 2011). Gasification of PE and PP has shown a promising result that can be applied to the treatment of used medical equipment such as masks and disinfectant container lids. Similar to pyrolysis, many studies on the gasification of waste rubber were reported, but the main focus was on used tires and not on waste gloves. The study conducted by Hazan et al. on NBR latex sludge waste showed that the sulfur content reached $0.73 \%$ by weight, so it was not possible to use it as a raw material for the gasification process (Hazan et al. 2019).

\section{Developing and implementing bio-based plastics}

Contemporary research is rigorously focusing on the development of eco-friendly alternatives to minimize the adverse effects and provide a sustainable solution to polymer/plasticinduced pollution (Sheldon and Norton 2020). Disposable, low-cost, lightweight, and renewable materials with adequate properties for rapid degradation in the environment need to be developed. Bioplastics (polymers that are partially or wholly obtained from biomass) provide innovative, viable, and most importantly, a sustainable but short-term alternative to conventional plastics as it replaces fossil fuels with renewable resources (Song et al. 2009). Bioplastics have the potential to reduce carbon dioxide emissions when breaking down and improve recycling goals (e.g., composting at home) as well as efficiency of waste management, and thereby reducing the massive plastic waste footprint (Oever et al. 2017). For instance, when decomposed in landfills, PLA produces almost $70 \%$ fewer greenhouse gases than PET. Biodegradable options offer additional benefits as they degrade by enzymatic or biological activity in open environments. A wide variety of biodegradable polymers such as PLA, polyethylene oxide (PEO), polycaprolactone (PCL), cellulose acetate (CA), polyvinyl alcohol (PVA), poly lactic-co-glycolic acid (PLGA), chitosan, alginate, or their blends are being utilized to develop and replace the SUP materials (Sheldon and Norton 2020, He et al. 2014, Sharma and Satapathy 2019a, 2019b, Sharma et al. 2020, 2021b, 2021c 2021d, Sharma and Satapathy 2021a, 2021b, Pandey et al. 2019). Thus, a key initiative favoring the fabrication of eco-friendly disposable single-use facemasks using microfibers, which can degrade or fragment into smaller particles of $<5 \mathrm{~mm}$, tend to reduce the apparent risk possibility. Presently, aliphatic polyesters like PHA and PLA and furanic-aliphatic polyesters, such as PEF and PEFco-PLA (polyethylene 2,5-furandicarboxylate-co-polylactic acid) are of particular interest as building-blocks for fabrication of PPE due to their sustainable thermophysical characteristics and tailorable degradation rates (Sousa et al. 2015, Mullapudi et al. 2018, Sharma and Satapathy 2021c).

\section{Nanoparticle-based (polymer modification) strategies to combat COVID-19}

Advanced nanotechnology-based materials are the backbone of a multitude of applications from designing masks and PPEs to specialized diagnostic tools to reduce the impact of COVID-19. Moreover, a broad range of physicochemical properties of nanomaterials tends to reduce the spread of COVID-19 infection. Nanotechnology offers new, cheaper, more durable, and safer materials for protection against biological and chemical hazards (Rajasekhar and Kanchi 2018). Protective equipment such as face masks, laboratory, or medical aprons developed via the incorporation of nano- 
additives tend to improve their physicomechanical performances, such as improving their barrier and antimicrobial properties without compromising the material texture or breathability (O'Dowd et al. 2020, Sharma and Satapathy 2021d, Mirza and Saha 2020, Sharma et al. 2021c). For instance, the use of hydrocarbon-based nanofibers, which are $\sim 3$ times smaller than cotton fibers, tends to prevent drip absorption due to the increase in surface area of the resultant materials. Similarly, techniques like nanoscale 3D surfaces, material structure, and/or hydrophobic nanoparticles coatings offer tremendous potential. For instance, the use of nanofibers in designing face masks tends to reduce breathing resistance due to a drop in the pressure buildup and protects against small particles $(<50 \mathrm{~nm}$ ) (GomollónBel 2020). Thus, such engineered face masks provide better protection than traditional surgical masks, which offer protection against particles/microbes with sizes ranging from 10 to $80 \mathrm{~nm}$ (Chua et al. 2020). However, N95/filtering facepiece (FFP2) face masks can only filter particles ranging from $\sim 100$ to $\sim 300 \mathrm{~nm}$ in size (Chua et al. 2020). Bose developed a biodegradable mask based on cellulose nanofibers capable of protecting against contaminants up to $100 \mathrm{~nm}$ in size (Bose 2020). Nanocellulose fibers were extracted from vegetable waste, including sugar cane cake and other agricultural waste. Kim et al. also prepared spike-like (3-(trimethoxy silyl) propyl dimethyl octadecyl ammonium chloride (Si-QAC)-based surface coatings. The authors reported the presence of covalent interaction between Si-QAC and PPE surface and thus evaluated the antiviral properties on various surfaces of PPEs (Kim et al. 2020).

Moreover, the use of textile materials incorporated with appropriate nano-additives tends to enhance the physicochemical attributes of textile materials, such as flame-resistant, selfcleaning, antimicrobial protection, and UV protection (Mao 2019). Fibers embedded in metal nanoparticles, like silver and copper nanoparticles, exhibit antiviral and antimicrobial properties (Sharma and Satapathy 2021e). Mao recently reported the applicability of nano-engineered protective clothing such as lab coats, aprons, and face masks (Mao 2019). The incorporation of metallic nanoparticles among engineered materials offers potential antimicrobial properties attributing to the low viability of the COVID-19 on a metallic surface such as copper. Park et al. demonstrated the applicability of the silver nanoparticles (in the form of hybrid silicon composites) in designing novel filters or membranes (Park et al. 2018). Such nanoparticles can potentially inactivate the influenza virus due to their interaction with the virus membrane (Sharma and Satapathy 2021d). More so, the surface modified by nanoscale biocidal like quaternary ammonium or quaternary phosphonates, peptides, or polymers can control the spread of microorganisms by oxidation of the microbial membrane. Thus, designing materials that can kill bacteria and viruses upon contact is important to prevent the spread of infection. For instance, Hsu et al. proposed an antiviral hydrophobic polycation coating of $\mathrm{N}, \mathrm{N}$-dodecyl methylpolyethyleneimine on the solid surface to disinfect various strains of the virus (Hsu et al. 2011). Thus, polymeric materials can be coated or encapsulated with such antimicrobial biocidal agents, to obtain sterile surfaces. Furthermore, disinfectants with silver salts are currently used for sterilizing purposes (Deshmukh et al. 2019). Bai et al., in their study, prepared (N-(2-hydroxypropyl)-3-trimethylammonium) propyl chitosan chloride (HTCC)-based electrospun fibers with simultaneous addition of graphene to remove $\sim 95 \%$ of porcine parvovirus (Bai et al. 2013). The hydrophobic and positively charged HTCC and graphene exhibited excellent virus repellent properties. HTCC is able to suppress the common pathogen HCoV-NL63, most likely due to the interaction with protein $\mathrm{S}$, which is necessary for coronavirus penetration (Milewska et al. 2013). Researchers at the Hong Kong University of Science and Technology have developed a multi-layered antimicrobial polymer layer (MAP-1) that effectively kills bacteria, viruses and even hard-to-kill spores and provides long-term protection against microbial infection to the public avenue (Ghosh 2020) . Thus, such novel materials designed for direct contact or release-induced destruction of microbes should be developed to control the spread of microbial infection.

New-age digital manufacturing technology, such as 3D printing is currently being used for designing inexpensive material substitutes using engineered polymeric filaments made of recycled thermoplastics (Sanchez-Rexach et al. 2020). In a recent review, Mikula et al. discussed the efficacy of recycled plastics in designing filaments for $3 \mathrm{D}$ printing machines. The authors also summarized the applicability of various commercially available, additive-incorporated filaments made from recycled polymers in food, clothing, packaging, and automobile sectors (Mikula et al. 2020).

\section{Exploring alternative vaccine packaging materials and delivery options: some choices}

In response to the increasing environmental concerns and the intricate logistics of mass vaccination, it is necessary to develop smart, innovative, and sustainable packaging materials for the safe storage and transportation of vaccines (Purkayastha et al. 2017). The potential approach for the management of plastic-based vaccine packaging waste is well illustrated in Fig. 11. The primary packaging plays a pivotal role in the preservation and safe transportation of the drug formulation. Nowadays, two plastic-based formats, which are a blow-fillseal (BFS) syringe, and silicon dioxide $\left(\mathrm{SiO}_{2}\right)$-coated plastic vials/syringes, are the potential packaging materials that are currently being used to address mass production and sound economics. Mostly, syringes made of either stainless steel, 


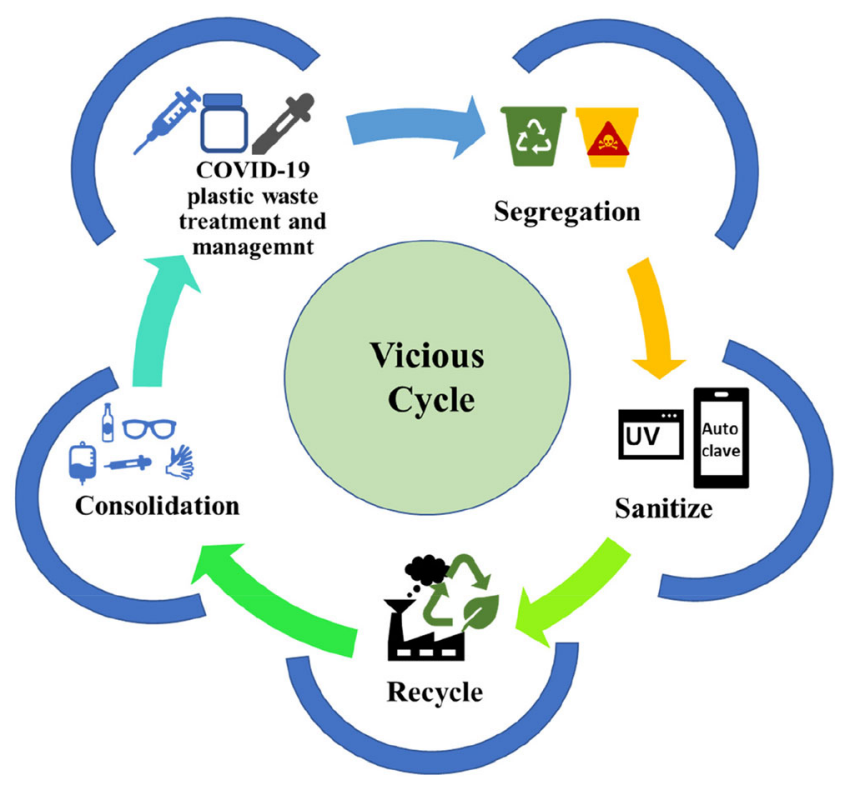

Can it be a choice??

Fig. 11 The vicious cycle for management of COVID-19 vaccine packaging material induced generated waste

glass, and plastics are used in the vaccine packaging. Plastic materials are user-friendly and robust with good barrier properties. Thus, it is imperative to scrutinize the use of alternative materials for designing syringes used for vaccination. Usually, syringes are made of polypropylene, which is safe and recyclable, though at the current pace, only $\sim 1 \%$ is recycled, and the rest is headed for the landfill (Azo Cleantech 2012). However, the non-biodegradability and the possible leaching of the incorporated toxic additives such as lead and cadmium, combined with the release of poisonous dioxins over a period of time and vinyl chlorides are also contributing to serious environmental concerns. Thus, the concept of pre-filled syringes mostly composed of plastic materials such as cycloolefin polymers and cycloolefin copolymers, launched by Cambridge Consultants, should be preferably adopted (Papania et al. 2018). Cycloolefin polymer is free from metal oxide residues resulting in minimum ash production post incineration. Prefilled syringes, unlike overfilled vials (usually 20-30\%), minimize product wastage (WHO 2011). Moreover, the non-essential secondary packaging with prefilled syringes tends to reduce the packaging waste by $30 \%$ and corresponding overall waste volume by $\sim 50 \%$ (WHO 2011). Compared with PP, cyclic olefin polymer and copolymers have lower oxygen and water vapor permeability and thereby allowing the possibility of long-term storage of vaccines. Additionally, it exhibits good compatibility with various terminal sterilization processes due to its biocompatibility and heat-resistant nature (Weikart and Langer 2020).

Recently, $\mathrm{SiO}_{2}$ materials science has patented a glasscoated plastic container, i.e., a promising non-traditional primary package with impressive scale-up potential. Borosilicate glass is one of the most widely used packaging materials. However, the questionable sealing integrity of ordinary glass at cold storage temperatures and the omnipresent problem of its breakage has limited its application in vaccine packaging vial production. Though SUPs have naturally received a surge of attention but have their inherent drawbacks that tend to compromise drug efficacy, and stability has always remained an issue. Therefore, $\mathrm{SiO}_{2}$ patented vials, i.e., hybrid glass and plastic materials, may act as potential materials to facilitate the effective storage and distribution of the COVID-19 vaccine. Such engineered vials are prepared by coating the interior of a medical-grade plastic container with pure $\mathrm{SiO}_{2}$-based nano-layers (Weikart and Langer 2020). Here, injection stretched blow-molded medical-grade cyclic olefin copolymer, or cyclic olefin polymer serves as the foundation followed by deposition of a thin (in $\mathrm{nm}$ ), glass-like barrier on the polymer surface via plasma-enhanced chemical vapor deposition (PECVD). The $\mathrm{SiO}_{2}$ vials, while providing excellent hydrolytic, chemical, mechanical, and thermal resistance, tend to solve significant challenges in the commercialization of vaccines and biological drugs. The $\mathrm{SiO}_{2}$ coated plastic-based packaging material also supports good drug stability, cryo, and cold storage container closure integrity, fillfinish compatibility, the rapid scale-up tendency with a secure supply chain, making it the best possible solution available currently for vaccine packaging (Weikart and Langer 2020).

Similarly, recent improvements in secondary packaging materials for sterile primary packaging such as PC 50 and HS 1000, which are a part of Placon's EcoStar ${ }^{\mathrm{TM}}$ line, rPET (recycled PET) offer exceptional clarity and impact resistance (Placon 2009). Such materials ensure $\sim 50-85 \%$ recycling rate, heat-sealing compatibilities and are less expensive than virgin polyethylene terephthalate glycol (PETG) and PET. Reportedly, EcoStar ${ }^{\mathrm{TM}}$ PC50 is a potential material to be used for designing vials, trays, clamshells, in-process trays, and glucose meter packaging. Similarly, EcoStar TM HS 1000 is a suitable material for medical environments such as the preparation, filling, and sealing operations which are usually performed indoors. The excellent heat-sealing properties of HS 1000 ensure its successful application as packaging materials for syringes which can further be sealed with foil or paper coating, thereby reducing the extent of plastic usage. HS 1000 can also be used with RF or ultrasonic sealing devices, which are commonly used in dental applications.

Expanded polystyrene (EPS) or Styrofoam is used for designing medical coolers for safe transportation of vaccines and medicines which are stable at low (usually sub-zero) temperatures. Such materials are very difficult to recycle and contribute $>350,000$ tonnes of packaging annually. Reportedly, an alternative to EPS foam ClimaCell ${ }^{\circledR}$ can potentially reduce carbon emissions by $\sim 65 \%$ (Smith 2020). Therefore, biodegradable polymers are a sustainable alternative to these SUPs 
if they can be produced sustainably and economically. Reportedly, green cell foam technology comprises a biodegradable, starch-based polymer, which provides thermal stability of up to $\sim 24$ to $48 \mathrm{~h}$ (Landaal Packaging systems 2012) (Butschli 2010). Such packaging materials tend to disintegrate within $\sim 4$ weeks upon dissolution in water and can be incinerated or burned cleanly. For instance, corn-starch-based foam, a potential alternative to EPS, is being used in designing shipping coolers which are nowadays being used to distribute Sandoz pharmaceutical products in overnight mail delivery of temperature-sensitive injectable liquids to customers of the USA. Similarly, a New Yorkbased biomaterials company, Evocative Design LLC, develops compostable plastics from agricultural byproducts and mushroom mycelium (Bayer and McIntyre 2020). In another development, Wool-cool packaging uses such compostable and renewable materials for thermal insulation (Fischer 2012). Nowadays, Cold pack airliners are being used for thermal insulation comprising of an inflatable insulating film that can be flattened and emptied for waste disposal (WHO 2011). Similarly, Softbox systems, a global enterprise, has developed a new thermal insulation foam that is fabricated using $\sim 100 \%$ recyclable materials with comparatively higher thermal efficiency than PS. Reportedly, Softbox has been known to maintain the cold chain for more than half of the world's 50 largest pharmaceutical companies (Softbox 2020). Furthermore, Sonoco ThermoSafe Greenbox is another company exploiting reusable packaging technology based on $\sim 100 \%$ biodegradable materials. Such phase change packaging materials tend to maintain the cold chain temperature for up to $\sim 6$ days and can be recycled and reused, thereby eliminating the need for other refrigerants (Fischer 2012). Approximately 20,000 re-uses have confirmed the excellent thermal-regulating properties of such materials. Representative images of some alternative primary and secondary packaging materials are shown in Fig. 12.

Similarly, foldable small-sized packaging materials tend to save space in the storage of goods and warehouses. Thus, the applicability of such materials can significantly reduce the environmental impact of vaccine packaging by reducing the amount of associated waste generated. For instance, Boehringer Ingelheim company is already using innovative blister packs for storage of novel effervescent vaccine tablets in place of traditional freeze-dried vaccine pellets, which otherwise are usually stored in glass vials. These technologies tend to reduce resource consumption and water footprint by $\sim 70 \%$, which may impact climate change by $\sim 80 \%$ (Boehringer 2020). Thus, not only developing novel alternatives but also judiciously selecting and adopting some of the available alternative temperature-sensitive vaccines may minimize the amount of packaging, storage, and transportationrelated non-recyclable plastic waste, which otherwise would be heaped due to COVID-19 management.

\section{Implementation of new policies and guidelines towards plastic waste management during the pandemic}

The current catastrophe has foisted some challenges, thereby providing an opportunity to introduce concrete solutions to plastic-induced pollution. For efficient management of these
Fig. 12 1(a) plastic vials with the interior lining of a microscopic layer of glass, (b) prefilled syringe for vaccination; 2(a) the EcoStar ${ }^{\mathrm{TM}}$ PC50 and HS 1000 by Placon for secondary packaging for diluents ampoules and vaccine vials, (b) corn-starch-based foam for shipping coolers, and (c) cold pack airliner new generation of Airliner® (Source: WHO 2011)

\section{Primary packaging}

(a)

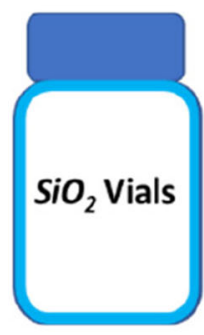

(b)

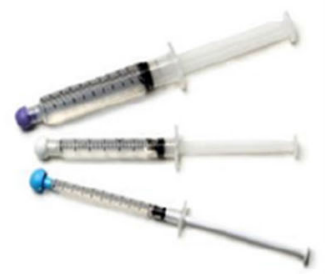

\section{Secondary packaging}

(a)

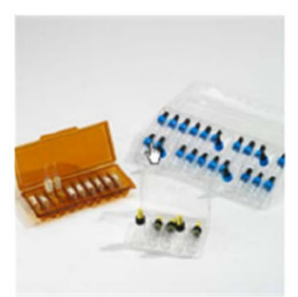

(b)

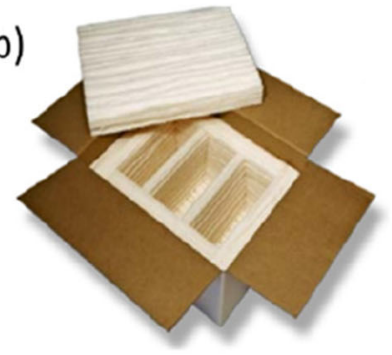

(c)

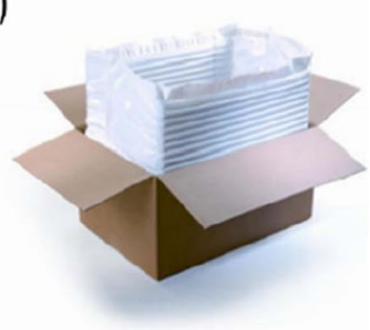


Table 4 Different guidelines issued by various organizations and agencies for the management of plastic-based COVID-19 waste

Organization Policy/recommendation References

International organization

Asian Development Bank (ADB)

World Health Organization (WHO) and UNICEF (WHO-UNICEF)

Union Nations Environment Programme (UNEP)

United Nations-Habitat (UN-Habitat)

National organization

Ministry of Ecology and Environment Management required for emergency disposal of hazardous COVID-19 waste (MEE)

Central Pollution Control Board (CPCB)

Occupational Safety and Health Administration (OSHA)

National System for Environmental Protection (SNPA)
COVID-19 Infectious solid waste (PPE included) should be wrapped twice before disposal/treatment.

Recycling activity should be avoided for the treatment of household/medical infectious COVID waste. It should be treated via sanitary landfilling or incineration.

Disposable gloves, masks, and gowns should be disposed of as environmentally harmful waste after each use and not reused

Contagious Waste generated during patient care, including confirmed infection with COVID-19 (for example, PPE, pathological waste) and must be collected safely in clearly marked lined containers and sharp, safe boxes, and then treated, preferably on-site and then safely disposed of.

Waste generated in the house during the quarantine should be packed in strong black bags and closed completely prior to the disposal and final collection by municipal waste services.

The most preferred treatment options for this infectious waste are autoclaving or a high-temperature dual-chamber incinerator.

Efficient disposal of healthcare and biomedical waste requires proper identification, separate collection, segregation, storage, transport, handling, and disposal under the hygiene and protection of personnel.

Contaminated medical waste should not be mixed with domestic waste; it must be collected by municipalities and waste disposal companies and disposed of separately from the other household stream and treated as household waste.

All potentially infectious waste should be placed in a colored bag (double bag if possible) tied with string or tape. They should be handled as residual waste not intended for material recovery.

Temporary local storage and heat treatment of potentially infectious waste of all the identified waste needs to be enforced.

When infectious waste cannot be heat treated, an appropriate and safe landfill should be put in place.

Enhance the frequency of waste collection and redesign the assets for waste collection based on the mapping of waste generation sources.

Prior to the heat treatment of infectious waste, it should be stored temporarily on-site for $72 \mathrm{~h}$.

Recycling of materials in multi-material recovery systems can be performed after proper storage of materials and subsequent sterilization.

should be a priority for medical waste disposal facilities.

Portable medical disposal treatment facilities such as hazardous waste incineration, industrial furnaces, and other facilities should be carried out in consultation with the relevant medical authorities.

Personal hygiene should be practiced while handling (storage, transport, and disposal) COVID-19 waste.

COVID-19 waste should be kept in two-layer plastic bags, and a separate color-coded bin must be used in isolation and COVID-19 intensive care center for proper segregation of waste.

Bags/containers used for collecting COVID-19 waste should be labeled as "COVID-19 waste."

The waste handler should maintain good hygiene when dealing with the infectious COVID-19 waste, such as used PPE, masks, and gloves.

Plastic-based waste should be sterilized, shredded, and then recycled.

Non-recyclable plastic waste should go for incineration.

Special attention should not be given to the COVID-19 contaminated waste. Waste management of contaminated waste should be the same as any other non-contaminated solid waste.

Safe work practices such as the use of PPE, puncture resistance gloves, eye and face protection must be adopted by workers to prevent exposure to infectious materials.

Based on the source of waste collection (COVID-19 impacted and non-impacted sources), contaminated plastic waste should be categorized.
(ADB 2020)

(WHO 2020d)

(UNEP 2020)

(UN-Habitat 2020)

(Ministry of Ecology and Environment 2020)
(OSHA 2020)

(SNPA 2020) 
Table 4 (continued)

\begin{tabular}{llc}
\hline Organization & Policy/recommendation & References \\
\hline & $\begin{array}{c}\text { Hazardous COVID-19 waste should be collected in two-layer bags and treated } \\
\text { separately. }\end{array}$ \\
$\begin{array}{c}\text { It is recommended to segregate hazardous waste generated from the COVID-19 } \\
\text { nen-impacted and impacted sources and keep it in a color-coded container. }\end{array}$ & $\begin{array}{c}\text { (Ministry of Health, } \\
\text { During the transportation of infectious waste to the treatment plant, it is important to } \\
\text { check for leakage or spillage in order to avoid contamination. } \\
\text { Infectious waste, including plastic-based protective equipment, must be autoclaved } \\
\text { or incinerated according to an appropriate safety protocol. }\end{array}$ \\
\hline
\end{tabular}

infectious and hazardous plastic-based waste during the COVID-19 pandemic, there is a prior need to address the challenges of processes such as identification of sources, collection, segregation, and transportation, handling, and adequate disposal with the hygiene and protection norms of the personnel remaining intact. Therefore, numerous international organizations like the UNICEF, WHO, European Commission, Asian Development Bank (ADB), UN-Habitat, UNEP, national health organizations, and apex pollution monitoring bodies such as Ministry of Ecology and Environment (MEE), China, Occupational Safety and Health Administration (OSHA), USA, Central Pollution Control Board (CPCB), India, Ministry of Health and Indigenous Medical Services, Sri Lanka, National System for Environmental Protection (SNPA), Italy and Ministry of Health and Population (MHP), Nepal, have recently issued a set of new guidelines and advisories to properly handle COVID-19-related biomedical and household wastes. Imperatively, these guidelines are to be implemented on the international and national levels, as summarized in Table 4.

Apart from the aforementioned guidelines, the new policies or frameworks need to be developed both nationally and internationally, with the integration of current waste minimization and recycling strategies, by considering the massive volumetric generation of plastic-based waste during the outbreak. Furthermore, the global community, material designers, and sustainability experts need to take a fresh look at the current policy to tackle the era of the pandemic. For instance, the recent guidelines of the US Centers for Disease Control and Prevention (CDC 2020), allow fully vaccinated Americans to avoid wearing masks when outdoors. By implementing such types of policies across the globe certainly helps to reduce the face mask-induced waste generation, which will help to develop waste control during this unprecedented COVID-19 outbreak. Thus, strong coordination between society, government, companies, and researchers is needed to achieve the best waste management solution through consumer responsibility, government-friendly policies, and innovative materials and research methods.

\section{Concluding remarks}

The COVID-19 pandemic exhibited the potential of plastic materials in safeguarding the health care personnel, and common citizens, especially the generally perceived SUPs stood out as a boon. However, the general perception of plastic as a polluter has continued to grow more rigorously and is attributed to the mismanagement and underutilization of resources resulting in a simultaneous increase in plastic consumption and waste generation. Considering the positive and negative roles of plastic in the time of the pandemic, a fair assessment suggests that irresponsible consumer behavior, poor awareness, and the burden on waste management establishments in terms of collection, segregation, processing, and financial constraints lead to mismanagement in waste treatment practices. Thus, systematic management and implementation of the circular economy strategies in terms of reduction, reuse, recycle, and recovery provide appropriate sustainable solutions. Further, initiatives to design and develop novel products with specific sterilization technologies such as the ones to be used in PPE may favor their large-scale reuse and reprocess. Moreover, the government's all-out efforts are required to motivate and influence both educational and research institutes in the plastic management domain by promoting new strategies to boost the confidence of millions of researchers and engineers. Such a paradigm shift brings out opportunities for numerous plastic engineers along with several environmental and economic benefits. Thus, the review summarizes the effects of the COVID-19 pandemic on the stupendous amount of plastic waste produced and some urgent appropriate measures to address the challenges in plastic waste treatment and disposal.

Thus, for post-COVID-19 control, several plastics and allied industries need to adopt new radical measures and sustainable approaches to reduce the economic risk, create new opportunities, and enhance the performance of both polymer manufacturers and plastic processors. Some of the salient strategies that may proactively be undertaken as the way forward are as below. 
- Development of biodegradable, bio-compostable, and body compatible polymers, plastics, products for largescale usage in packaging, PPEs, and other COVID-19 care accessories for healthcare workers and, if appropriate to extend their usage in clinical environments.

- Development of novel antimicrobial eco-friendly surface coatings for COVID-19 care devices.

- Process optimization to product design, quality validation, and policy implementation favoring novel agro-based and bio-based products as partly/fully substitutable alternatives to devices that are currently in use for COVID-19 management.

- New material consolidation using aliphatic polyesters (PLA, PCL, polyhydroxy butyrates, etc.), surface modified polyolefins (PP, PE): transparent clothing and lightweight, porous breathable fabric alternatives such as nonwovens.

- Large scale plastic biomedical waste segregation facility establishment away from human settlements at a distance of significance

- Automating the waste segregation to make the COVID-19 waste dump-yard workers less risk-prone

- Sanitization facility and sterilization of PPE and other COVID-19 care/prevention-related waste

- Developing novel methods for large-scale sterilization of biomedical waste, using UV, ozone, or other cheap, affordable, effective, and portable technologies.

- Integrating the recyclability of used/rejected COVID-19 care products, packaging goods, gloves, PPEs, and other vaccination-related plastic wastes conforming to "wasteto-energy or waste-to-use" material life cycle ideology

- Promoting newer alternatives to reduce the tonnage by alternative design and production with enhanced breathability, porous structure enabled PPEs and incorporating the use of natural products in the polymers instead of using them virgin.

Nevertheless, a comprehensive victory of the world community over the ongoing crisis dealing with plastic waste generation and its sustainable carbon-neutral policy-based solutions appears to be the urgent need at this hour of recurring waves of Corona. This adoption of a hierarchical prioritization strategy for materials, based on disposability, biodegradability, reusability, and large-scale cost-effective productivity, remains as much in the hands of the technocrats and environmental policymakers as in the hands of material scientists and medical practitioners.

Authors' contributions Krishna Priyadarshini Das: conceptualization, methodology, data curation, visualization, writing - original draft preparation; Deepika Sharma: conceptualization, methodology, supervision, formal analysis, writing - reviewing and editing, visualization, validation; Sampa Saha: writing - reviewing, visualization, supervision, validation; Bhabani K. Satapathy: resources, writing-review and editing, visualization, supervision, formal analysis, validation.

Funding The current research was supported by financial support from MHRD (Ministry of Human Resource and Development), India.

Data availability All data generated or analyzed during this study are included in this published article.

\section{Declarations}

Ethics approval and consent to participate Not applicable.

Consent for publication Not applicable.

Competing interests The authors declare that they have no conflict of interest.

\section{References}

Abnisa F, Wan Daud WMA (2014) A review on co-pyrolysis of biomass: an optional technique to obtain a high-grade pyrolysis oil. Energy Convers Manag 87:71-85. https://doi.org/10.1016/j.enconman. 2014.07.007

$\mathrm{ACR}+$, (2020). Municipal waste management and COVID-19. Association of cities and regions for sustainable resource management (ACR+). https://www.acrplus.org/en/municipal-wastemanagement-covid-19. (Accessed 3 May 2021)

ADB (2020). Managing infectious waste during the COVID-19 pandemic. Asian Dev Bank (ADB). https://www.adb.org/publications/ managing-medical-waste-covid19. (Accessed 5 May 2021)

Adolfsson KH, Lin C, Hakkarainen M (2018) Microwave-assisted hydrothermal carbonization and solid state postmodification of carbonized polypropylene. ACS Sustain Chem Eng 6:11105-11114. https://doi. org/10.1021/acssuschemeng.8b02580

Al-Qahtani AA (2020) Severe acute respiratory syndrome coronavirus 2 (SARS-CoV-2): emergence, history, basic and clinical aspects. Saudi J Biol Sci 27:2531-2538. https://doi.org/10.1016/j.sjbs. 2020.04.033

Al-Sayah MH (2020) Chemical disinfectants of COVID-19: an overview. J Water Health 18:843-848. https://doi.org/10.2166/wh.2020.108

Amaral REC, Brito J, Buckman M, Drake E, Ilatova E, Rice P, Sabbagh C, Voronkin S, Abraham YS (2020) Waste management and operational energy for sustainable buildings: a review. Sustain. 12 . https://doi.org/10.3390/su12135337

Andrady AL, Neal MA (2009) Applications and societal benefits of plastics. Philos Trans R Soc B Biol Sci 364:1977-1984. https://doi.org/ 10.1098/rstb.2008.0304

Anis S, Zainal ZA (2011) Tar reduction in biomass producer gas via mechanical, catalytic and thermal methods: a review. Renew Sust Energ Rev 15:2355-2377. https://doi.org/10.1016/j.rser.2011.02. 018

Asadi S, Wexler AS, Cappa CD, Barreda S, Bouvier NM, Ristenpart WD (2019) Aerosol emission and super emissions during human speech increase with voice loudness. Sci Rep 9:1-10. https://doi.org/10. 1038/s41598-019-38808-Z

Asadi S, Bouvier N, Wexler AS, Ristenpart WD (2020) The coronavirus pandemic and aerosols: does COVID-19 transmit via expiratory particles? Aerosol Sci. Technol. 54:635-638. https://doi.org/10. 1080/02786826.2020.1749229

Aydogdu MO, Altun E, Chung E, Ren G, Homer-Vanniasinkam S, Chen B, Edirisinghe M (2021) Surface interactions and viability of 
coronaviruses. J R Soc Interface 18:20200798. https://doi.org/10. 1098/rsif.2020.0798

Azo Cleantech. 2012. Recycling of polypropylene (PP), https://www. azocleantech.com/amp/article.aspx?ArticleID=240. (Accessed 7 May 2021)

Bai B, Mi X, Xiang X, Heiden PA, Heldt CL (2013) Non-enveloped virus reduction with quaternized chitosan nanofibers containing graphene. Carbohydr Res 380:137-142. https://doi.org/10.1016/j.carres.2013. 08.020

Basu M, (2020). Today's PPE kits could be tomorrow's roads, fuel CSIR's plan to tackle Covid plastic surge. ThePrint 1-6, https:// theprint.in/health/todays-ppe-kits-could-be-tomorrows-roads-fuelcsirs-plan-to-tackle-covid-plastic-surge/478760/.(Accessed 29 July 2021)

Bayer E, McIntyre G, (2020). Ecovative Design, https://www.epo.org/ news-events/events/european-inventor/finalists/2019/bayer.html. (Accessed 2 May 2021)

BBC, (2020). COVID-19: How Long Does the Coronavirus Last on Surfaces. Brtish Broadcasting Corporation (BBC). https://www. bbc.com/future/article/20200317-covid-19-how-long-does-thecoronavirus-last-on-surfaces. (Accessed 21 April 2021)

Bengali S, (2020). COVID-19 pandemic creates tidal wave of plastic waste - Los Angeles Times. Los Angeles Times, https://www. latimes.com/world-nation/story/2020-06-13/coronavirus-pandemicplastic-waste-recycling. (Accessed 3 May 2021)

Bhardwaj R, Agrawal A (2020) Likelihood of survival of coronavirus in a respiratory droplet deposited on a solid surface. Phys Fluids 32:1-6. https://doi.org/10.1063/5.0012009

BIR, (2020). BIR- News - Covid-19 update: fragmented picture for the under-pressure recycling industry, https://www.bir.org/news-press/ covid-19-info-center/item/covid-19-update-fragmented-picture-forunder-pressure-recycling-industry. (Accessed 5 May 2021)

Blanchard J (2007) Preventing health care-associated infections. AORN J 86:547-576. https://doi.org/10.1016/j.aorn.2007.11.013

Boehringer I, (2020). Neo-smart and sustainable vaccine, https://www. boehringer-ingelheim.com/animal-health/our-responsibility/neosmart-and-sustainable-vaccines. (Accessed 23 April 2021)

Bose P, (2020). Nanotechnology in washable and reusable face masks. Azo Nano 1-3, https://www.azonano.com/article.aspx?ArticleID= 5529. (Accessed 3 May 2021)

Bown CP, (2020). COVID-19: China's exports of medical supplies provide a ray of hope | PIIE. Peterson Inst. Int. Econ. https://www.piie. $\mathrm{com} / \mathrm{blogs} /$ trade-and-investment-policy-watch/covid-19-chinasexports-medical-supplies-provide-ray-hope. (Accessed 7 May 2021)

Bracco G, Holst B (2013) Surface science techniques, Springer Series in Surface. Sciences. https://doi.org/10.1007/978-3-642-34243-1

Bratovcic A (2021) Available recycling solutions for increased personal protective equipment in the environment due to the COVID-19 pandemic. Aswan Univ J Environ Stud. https://doi.org/10.21608/aujes. 2021.57293.1009

Budsaereechai S, Hunt AJ, Ngernyen Y (2019) Catalytic pyrolysis of plastic waste for the production of liquid fuels for engines. RSC Adv 9:5844-5857. https://doi.org/10.1039/c8ra10058f

Butschli J, (2010). Biodegradable foam protects Sandoz s shipments. Packaging world. https://www.packworld.com/design/protectivetransport-packaging/article/13346978/biodegradable-foamprotects-sandozs-shipments. (Accessed 23 April 2021)

Castañ N, Cordts SC, Jalil MK, Zhang KS, Koppaka S, Bick AD, Paul R, Tang SKY (2021) Fomite transmission, physicochemical origin of virus-surface interactions, and disinfection strategies for enveloped viruses with applications to SARS-CoV-2. ACS Omega 6:65096527. https://doi.org/10.1021/acsomega.0c06335

CDC, (2020). The National Institute for Occupational Safety and Health recommended guidance for extended use and limited reuse of N95 Filtering facepiece respirators in healthcare settings, https://www. cdc.gov/niosh/topics/hcwcontrols/recommendedguidanceextuse. html. (Accessed 3 May 2021)

Chin AWH, Chu JTS, Perera MRA, Hui KPY, Yen H-L, Chan MCW, Peiris M, Poon LLM (2020) Stability of SARS-CoV-2 in different environmental conditions. Lancet Microbe 1:e10. https://doi.org/10. 1016/s2666-5247(20)30003-3

Chow Y, Master F, Birsel R, (2020). Discarded coronavirus masks clutter Hong Kong's beaches, trails, Reuters. https://www.reuters.com/ article/us-health-coronavirus-hongkong-environme/discardedcoronavirus-masks-clutter-hong-kongs-beaches-trailsidUSKBN20Z0PP. (Accessed 5 May 2021)

Chu Y, Huang C, Xie X, Tan B, Kamal S, Xiong X (2018) Multilayer hybrid deep-learning method for waste classification and recycling. Comput Intell Neurosci. https://doi.org/10.1155/2018/5060857

Chua MH, Cheng W, Goh SS, Kong J, Li B, Lim JYC, Mao L, Wang S, Xue K, Yang L, Ye E, Zhang K, Cheong WCD, Tan BH, Li Z, Tan BH, Loh XJ (2020) Face masks in the new COVID-19 normal: materials, testing, and perspectives. Res (Washington, DC) 2020: 7286735. https://doi.org/10.34133/2020/7286735

Cook TM (2020) Personal protective equipment during the coronavirus disease (COVID) 2019 pandemic - a narrative review. Anaesthesia 75:920-927. https://doi.org/10.1111/anae.15071

Corburn J, Vlahov D, Mberu B, Riley L, Caiaffa WT, Rashid SF, Ko A, Patel S, Jukur S, Martínez-Herrera E, Jayasinghe S, Agarwal S, Nguendo-Yongsi B, Weru J, Ouma S, Edmundo K, Oni T, Ayad H (2020) Slum health: arresting COVID-19 and improving wellbeing in urban informal settlements. J Urban Health 97:348-357. https://doi.org/10.1007/s11524-020-00438-6

Cozier M (2020) Disposing of PPE responsibly is essential, https://www. soci.org/news/2020/7/disposing-of-ppe-responsibly-is-essential. (Accessed 3 May 2021)

CPCB, (2020). Guidelines for handling, treatment and disposal of waste generated during treatment/diagnosis/quarantine of COVID-19 patients, http://cpcbenvis.nic.in/pdf/1595918059_mediaphoto2009. pdf. (Accessed 7 May 2021)

CU-Boulder, (2008). Disinfectants and sterilization methods. Environ. Heal. Saf. Guidel. 14, https://ehs.colorado.edu/resources/ disinfectants-and-sterilization-methods/. (Accessed 25 April 2021)

da Costa VG, Moreli ML, Saivish MV (2020) The emergence of SARS, MERS and novel SARS-2 coronaviruses in the 21st century. Arch Virol 165:1517-1526. https://doi.org/10.1007/s00705-020-04628-0

Das AK, Islam MN, Billah MM, Sarker A (2021) COVID-19 and municipal solid waste (MSW) management: a review. Environ Sci Pollut Res. https://doi.org/10.1007/s11356-021-13914-6

DEFRA, (2020). Guidance on prioritising waste collection services during coronavirus (COVID-19) pandemic. https://www.gov.uk/ government/publications/coronavirus-covid-19-advice-to-localauthorities-on-prioritising-waste-collections/guidance-onprioritising-waste-collection-services-during-coronavirus-covid-19pandemic. (Accessed 9 May 2021)

Demirbas A (2004) Pyrolysis of municipal plastic wastes for recovery of gasoline-range hydrocarbons. J Anal Appl Pyrolysis 72:97-102. https://doi.org/10.1016/j.jaap.2004.03.001

Dente SMR, Hashimoto S (2020) COVID-19: a pandemic with positive and negative outcomes on resource and waste flows and stocks. Resour Conserv Recycl 161:104979. https://doi.org/10.1016/j. resconrec.2020.104979

Deshmukh SP, Patil SM, Mullani SB, Delekar SD (2019) Silver nanoparticles as an effective disinfectant: a review. Mater Sci Eng C Mater Biol Appl 97:954-965. https://doi.org/10.1016/j.msec.2018. 12.102

Dhakate PD, (2020). Polymer - our saviour during Covid-19 pandemic. Int Res J Eng Technol 3472-3476. https://www.irjet.net/archives/ V7/i9/IRJET-V7I9613.pdf. (Accessed 9 May 2021)

Dhand R, Li J (2020) Coughs and sneezes: their role in transmission of respiratory viral infections, including SARS-CoV-2. Am J Respir 
Crit Care Med 202:651-659. https://doi.org/10.1164/rccm.202004$1263 \mathrm{PP}$

Duer J, (2020). Single-use plastics are on the rise due to COVID-19. World Econ. Forum. https:/www.weforum.org/agenda/2020/07/ plastic-waste-management-covid19-ppe/. Accessed 9 May 2021

Dwivedi P, Mishra PK, Mondal MK, Srivastava N (2019) Nonbiodegradable polymeric waste pyrolysis for energy recovery. Heliyon 5:e02198-e02198. https://doi.org/10.1016/j.heliyon.2019. e02198

Edwards E, (2020). How are Goggles Made? https://www.thomasnet. com/articles/plant-facility-equipment/how-are-goggles-made/ (Accessed 13 May 2021)

Eriksen M, Mason S, Wilson S, Box C, Zellers A, Edwards W, Farley H, Amato S (2013) Microplastic pollution in the surface waters of the Laurentian Great Lakes. Mar Pollut Bull 77:177-182. https://doi. org/10.1016/j.marpolbul.2013.10.007

Eriksen M, Lebreton LCM, Carson HS, Thiel M, Moore CJ, Borerro JC, Galgani F, Ryan PG, Reisser J (2014) Plastic pollution in the world's oceans: more than 5 trillion plastic pieces weighing over 250,000 tons afloat at sea. PLoS One 9:1-15. https://doi.org/10. 1371/journal.pone.0111913

Ewbank AC, Sacristán C, Costa-Silva S, Antonelli M, Lorenço JR, Nogueira GA, Ebert MB, Kolesnikovas CKM, Catão-Dias JL (2020) Postmortem findings in Magellanic penguins (Spheniscus magellanicus) caught in a drift gillnet. BMC Vet Res 16:1-10. https://doi.org/10.1186/s12917-020-02363-x

FakhrHoseini SM, Dastanian M (2013) Predicting pyrolysis products of PE, PP, and PET using NRTL activity coefficient model. J Chemother 2013:487676. https://doi.org/10.1155/2013/487676

Ferrier S, Ninan KN, Leadley P, Alkemade R, Acosta LA, Akçakaya HR, Brotons L, Cheung W, Christensen V, Harhash KA, KabuboMariara J, Lundquist C, Obersteiner M, Pereira H, Peterson G, Pichs-Madruga R, Ravindranath NH, Rondini C, Wintle B, (2019). Summary for policymakers of the methodological assessment of scenarios and models of biodiversity and ecosystem services of the Intergovernmental Science-Policy Platform on Biodiversity and Ecosystem Services. Secr Intergov Sci Platf Biodivers Ecosyst Serv 39.

Ferronato N, Torretta V (2019) Waste mismanagement in developing countries: a review of global issues. Int J Environ Res Public Health 16. https://doi.org/10.3390/ijerph16061060

Fischer E (2012) Diminishing vaccine wastage: next-gen of temperaturecontrolled packaging. Pharm Technol. http://www.pharmaceuticaltechnology.com/features/featurediminishing-vaccine-wastage-thenext-gen-of-temperature-controlled-packaging/. (Accessed 13 May 2021)

Geyer R, Jambeck JR, Law KL (2017) Production, use, and the fate of all plastics ever made. Sci Adv 3:e1700782. https://doi.org/10.1126/ sciadv. 1700782

Ghosh, (2020). Anti-viral surface coating to prevent spread of novel coronavirus (COVID-19) through touch. https://www.coatingsworld. com/content-microsite/cw covid-19/2020-04-15/anti-viral-surfacecoating-to-prevent-spread-of-novel-coronavirus-covid-19-throughtouch. (Accessed 3 May 2021)

Gomollón-Bel F, 2020. Nanofibers put a new spin on COVID-19 masks. Chem Eng News 21-23. https://doi.org/10.47287/cen-09845feature2

Gray R, (2020). Covid-19: How long does the coronavirus last on surfaces. Bbc, https://www.bbc.com/future/article/20200317-covid-19how-long-does-the-coronavirus-last-on-surfaces. (Accessed 5 May 2021)

Guern CL, (2019). When the mermaids cry : the great plastic tide. Coastal Care. https://plastic-pollution.org/. (Accessed 23 April 2021)

Gunia A, (2020). There aren t enough medical masks to fight coronavirus. here s why it s not going to get better anytime soon. Time, https:// time.com/5785223/medical-masks-coronavirus-covid-19/. (Accessed 13 May 2021)

Hanoğlu A, Çay A, Yanık J (2019) Production of biochars from textile fibres through torrefaction and their characterisation. Energy 166: 664-673. https://doi.org/10.1016/j.energy.2018.10.123

Hazan MA, Mamat MS, Ismail I, Hussein MZ, Yaakob Y (2019) Fractionation of waste nitrile butadiene rubber (NBR) latex sludge. AIP Conf Proc 2151:020012. https://doi.org/10.1063/1.5124642

He A, Li S, Ma J, Yang Z (2014) Environmental friendly polymer materials for sustainable development. Int J Polym Sci 2014:107028. https://doi.org/10.1155/2014/107028

Hebner TS, Maurer-Jones MA (2020) Characterizing microplastic size and morphology of photodegraded polymers placed in simulated moving water conditions. Environ Sci Process Impacts 22:398 407. https://doi.org/10.1039/c9em00475k

Heidbreder LM, Bablok I, Drews S, Menzel C (2019) Tackling the plastic problem: a review on perceptions, behaviours, and interventions. Sci Total Environ 668:1077-1093. https://doi.org/10.1016/j.scitotenv. 2019.02.437

Henneberry B, (2020). How surgical masks are made, tested and used. Thomas Ind. Update, https://www.thomasnet.com/articles/other/ how-surgical-masks-are-made/. (Accessed 27 April 2021)

Hopewell J, Dvorak R, Kosior E (2009) Plastics recycling: challenges and opportunities. Philos Trans R Soc B Biol Sci 364:2115-2126. https://doi.org/10.1098/rstb.2008.0311

Hossain MF, Hasana S, Mamun AA, Uddin MS, Wahed MII, Sarker S, Behl T, Ullah I, Begum Y, Bulbul IJ, Amran MS, Rahman MH, BinJumah MN, Alkahtani S, Mousa SA, Aleya L, Abdel-Daim MM (2020) COVID-19 outbreak: pathogenesis, current therapies, and potentials for future management. Front Pharmacol. https://doi.org/ 10.3389/fphar.2020.563478

Hsu BB, Yinn Wong S, Hammond PT, Chen J, Klibanov AM (2011) Mechanism of inactivation of influenza viruses by immobilized hydrophobic polycations. Proc Natl Acad Sci 108:61-66. https://doi. org/10.1073/pnas. 1017012108

Hyun MC, (2020). Korea sees steep rise in online shopping during COVID-19 pandemic. ZD Net, https://www.zdnet.com/article/ korea-sees-steep-rise-in-online-shopping-during-covid-19pandemic/. (Accessed 8 May 2021)

IEA, (2020). Oil Market Report - April 2020. Int. Energy Agency, https:// www.iea.org/reports/oil-market-report-april-2020. (Accessed 13 May 2021)

Jaski EB (1973) The Educon: let's dream awhile! J Teach Educ. https:// doi.org/10.1177/002248717302400108

Jayaweera M, Perera H, Gunawardana B, Manatunge J (2020) Transmission of COVID-19 virus by droplets and aerosols: a critical review on the unresolved dichotomy. Environ Res 188:109819. https://doi.org/10.1016/j.envres.2020.109819

Jensen F, Schuettler D, (2018). Sperm whale washed up in Indonesia had plastic bottles, bags in stomach. Reuters $1-5$, https://www.reuters. com/article/instant-article/idUKKCN1NP11H. (Accessed 8 May 2021)

Jessop ZM, Dobbs TD, Ali SR, Combellack E, Clancy R, Ibrahim N, Jovic TH, Kaur AJ, Nijran A, O’Neill TB, Whitaker IS (2020) Personal protective equipment for surgeons during COVID-19 pandemic: systematic review of availability, usage and rationing. $\mathrm{Br} \mathrm{J}$ Surg 107:1262-1280. https://doi.org/10.1002/bjs.11750

Jeswani H, Smith R, Azapagic A (2012) Energy from waste: carbon footprint of incineration and landfill biogas in the UK. Int J Life Cycle Assess 18:218-229. https://doi.org/10.1007/s11367-0120441-8

Kalina M, Tilley E (2020) "This is our next problem": cleaning up from the COVID-19 response. Waste Manag 108:202-205. https://doi. org/10.1016/j.wasman.2020.05.006

Kampf G, Todt D, Pfaender S, Steinmann E, (2020). Persistence of coronaviruses on inanimate surfaces and their inactivation with 
biocidal agents. J Hosp Infect J 19-21. https://doi.org/10.1016/j. jhin.2020.01.022

Karia R, Gupta I, Khandait H, Yadav A, Yadav A (2020) COVID-19 and its modes of transmission. SN Compr Clin Med 2:1798-1801. https://doi.org/10.1007/s42399-020-00498-4

Karim N, Afroj S, Lloyd K, Oaten LC, Andreeva DV, Carr C, Farmery AD, Kim ID, Novoselov KS (2020) Sustainable personal protective clothing for healthcare applications: a review. ACS Nano 14:1231312340. https://doi.org/10.1021/acsnano.0c05537

Kaur I, Behl T, Aleya L, Rahman H, Kumar A, Arora S, Bulbul IJ (2021) Artificial intelligence as a fundamental tool in management of infectious diseases and its current implementation in COVID-19 pandemic. Environ Sci Pollut Res Int 25:1-18. https://doi.org/10.1007/ s11356-021-13823-8

Kchaou M, Abuhasel K, Khadr M, Hosni F, Alquraish M (2020) Surface disinfection to protect against microorganisms: overview of traditional methods and issues of emergent nanotechnologies. Appl Sci 10. https://doi.org/10.3390/app10176040

Kilinc FS (2015) A review of isolation gowns in healthcare: fabric and gown properties. J Eng Fiber Fabr 10:180-190

Kim Y, Youn H, Kim J, Lee D, Go S, Park J, Lee S, Noh J, Nahm S-S (2020) Potential use of 3-(trimethoxysilyl)propyldimethyl octadecyl ammonium chloride as an antimicrobial and antiviral agent for the disinfection of personal protective equipment. Clin Exp Vaccine Res 9:174. https://doi.org/10.7774/cevr.2020.9.2.174

Klemeš JJ, Van Fan Y, Tan RR, Jiang P (2020) Minimising the present and future plastic waste, energy and environmental footprints related to COVID-19. Renew Sust Energ Rev 127:109883. https://doi.org/ 10.1016/j.rser.2020.109883

Konov D, (2020). COVID-19 is forcing us to rethink our plastic problem. World Econ. Forum, https://www.weforum.org/agenda/2020/05/ covid-19-is-forcing-us-to-rethink-our-plastic-problem/. (Accessed 23 April 2021)

Kratzel, (2020). Efficient inactivation of SARS-CoV-2 by WHOrecommended hand rub formulations and alcohols. BioRxiv, https://www.biorxiv.org/content/10.1101/2020.03.10.986711v1. (Accessed 7 May 2021)

Krishnakumar G, (2021). Coronavirus | India witnesses surge in COVID19-related biomedical waste. https://www.thehindu.com/news/ national/coronavirus-india-witnesses-surge-in-covid-19-relatedbiomedical-waste/article34563675.ece. (Accessed 17 May 2021)

Kulkarni BN, Anantharama V (2020) Repercussions of COVID-19 pandemic on municipal solid waste management: challenges and opportunities. Sci Total Environ 743:140693. https://doi.org/10.1016/j. scitotenv.2020.140693

Kumar A, Samadder SR (2017) A review on technological options of waste to energy for effective management of municipal solid waste. Waste Manag 69:407-422. https://doi.org/10.1016/j.wasman.2017. 08.046

LA Times (2020) The COVID-19 Pandemic Is Unleashing a Tidal Wave of Plastic Waste. LosAngeles Times (LA Times). https://www. latimes.com/world-nation/story/2020-06-13/coronavirus-pandemicplastic-waste-recycling. (Accessed 9 April 2021)

Landaal Packaging systems, (2012). Landaal provides polystyrene replacement Green Cell Foam ${ }^{\circledR}$ thermal shippers to Wisconsinbased tropical traditions. https:/www.landaal.com/about-landaalpackaging-family-owned-business/in-the-news-2009-2013/tropicaltraditions-replaces-polystyrene-with-landaals-green-cell-foamthermal-shippers/. (Accessed 7 May 2021)

Li Y, Zhang Z, Yang L, Lian X, Xie Y, Li S, Xin S, Cao P, Lu J (2020) The MERS-CoV receptor DPP4 as a candidate binding target of the SARS-CoV-2 spike. iScience 23:101160. https://doi.org/10.1016/j. isci.2020.101160

Lindsay SW, Wilson A, Golding N, Scott TW, Takken W (2017) Improving the built environment in urban areas to control Aedes aegypti-borne diseases. Bull World Health Organ 95:607-608. https://doi.org/10.2471/BLT.16.189688

Lopez G, Artetxe M, Amutio M, Alvarez J, Bilbao J, Olazar M (2018) Recent advances in the gasification of waste plastics. A critical overview. Renew Sustain Energy Rev 82:576-596. https://doi.org/ 10.1016/j.rser.2017.09.032

Lu R, Zhao X, Li J, Niu P, Yang B, Wu H, Wang W, Song H, Huang B et al (2020) Genomic characterisation and epidemiology of 2019 novel coronavirus: implications for virus origins and receptor binding. Lancet 395:565-574. https://doi.org/10.1016/S0140-6736(20) 30251-8

Ma B, Li X, Jiang Z, Jiang J (2019) Recycle more, waste more? When recycling efforts increase resource consumption. J Clean Prod 206: 870-877. https://doi.org/10.1016/j.jclepro.2018.09.063

Malinauskaite J, Jouhara H, Czajczyńska D, Stanchev P, Katsou E, Rostkowski P, Thorne RJ, Colón J, Ponsá S, Al-Mansour F, Anguilano L, Krzyżyńska R, López IC, Vlasopoulos A, Spencer N (2017) Municipal solid waste management and waste-to-energy in the context of a circular economy and energy recycling in Europe. Energy 141:2013-2044. https://doi.org/10.1016/j.energy.2017.11. 128

Mao N, (2019). Textile materials for protective textiles, in: Highperformance technical textiles. John Wiley \& Sons, Ltd, 107-157. https://doi.org/10.1002/9781119325062.ch5

Markets and Markets (2020) COVID-19 Impact on Packaging Market by Material Type (Plastics/Polymers, Paper \& Paperboard, Glass and Metal), Application (Healthcare, Food \& Beverages, Household Hygiene, Beauty \& Personal Care and Electrical \& Electronics) and Region - Global Forecast to 2021. https://www. researchandmarkets.com/reports/5024117/covid-19-impactonpackaging-market-by-material. (Accessed 11 April 2021)

Mastellone ML, Zaccariello L, Arena U (2010) Co-gasification of coal, plastic waste and wood in a bubbling fluidized bed reactor. Fuel 89: 2991-3000. https://doi.org/10.1016/j.fuel.2010.05.019

MEWR, NEA, (2019). Zero Waste Masterplan, https://www. towardszerowaste.gov.sg/images/zero-waste-masterplan.pdf. (Accessed 23 April 2021)

Microbe Notes, 2020. online microbiology and biology study notes, electron microscopy(SEM and TEM) image of SAR-COV-2, https:// microbenotes.com/electron-microscopy-images-of-sars-cov-2/. (Accessed 9 May 2021)

Mikula K, Skrzypczak D, Izydorczyk G, Warchoł J, Moustakas K, Chojnacka K, Witek-Krowiak A (2020) 3D printing filament as a second life of waste plastics - a review. Environ Sci Pollut Res 28: 12321-12333. https://doi.org/10.1007/s11356-020-10657-8

Milewska A, Ciejka J, Kaminski K, Karewicz A, Bielska D, Zeglen S, Karolak W, Nowakowska M, Potempa J, Bosch BJ, Pyrc K, Szczubialka K (2013) Novel polymeric inhibitors of HCoV-NL63. Antivir Res 97:112-121. https://doi.org/10.1016/j.antiviral.2012.11. 006

Ministry of Ecology and Environment, (2020). Management and technical guidelines for emergency disposal of medical waste infected by the novel coronavirus pneumonia epidemic ( Trial ). http://www.fao. org/faolex/results/details/fr/c/LEX-FAOC197697/. (Accessed 13 May 2021)

Ministry of Health, (2020). Guidelines for Handling, Treatment, and Disposal of Waste Generated during Treatment/Diagnosis/ Quarantine of COVID-19 Patients. https://cpcb.nic.in/uploads/ Projects/Bio-Medical-Waste/BMWGUIDELINES-COVID_1.pdf. (Accessed 21 April 2021)

Miranda R, Yang J, Roy C, Vasile C (2001) Vacuum pyrolysis of commingled plastics containing PVC I. Kinetic study. Polym Degrad Stab 72:469-491. https://doi.org/10.1016/S0141-3910(01) 00048-9

Mirza I, Saha S (2020) Biocompatible anisotropic polymeric particles: synthesis, characterization, and biomedical applications. ACS Appl 
Bio Mater 3(12):8241-8270. https://doi.org/10.1021/acsabm. 0c01075

Mohapatra, S., 2017. Chapter 59 - Sterilization and disinfection. Essentials of Neuroanesthesia 929-944. https://doi.org/10.1016/ B978-0-12-805299-0.00059-2

Monella L, (2020). Will plastic pollution get worse after the COVID-19 pandemic? Euronews, https://www.euronews.com/2020/05/12/willplastic-pollution-get-worse-after-the-covid-19-pandemic. (Accessed 3 May 2021)

Mostaghimi A, Antonini M-J, Plana D, Anderson PD, Beller B, Boyer EW, Fannin A et al (2020) Regulatory and safety considerations in deploying a locally fabricated, reusable face shield in a hospital responding to the COVID-19 pandemic. Med 1:139-151.e4. https://doi.org/10.1016/j.medj.2020.06.003

Moustafa H, Youssef AM, Darwish NA, Abou-Kandil AI (2019) Ecofriendly polymer composites for green packaging: future vision and challenges. Compos Part B Eng 172:16-25. https://doi.org/10.1016/ j.compositesb.2019.05.048

Mullapudi SS, Pandey K, Maiti SN, Saha S (2018) PLA/EVA/teak wood flour biocomposites for packaging application: evaluation of mechanical performance and biodegradation properties. J Package Technol Res 2:191-201. https://doi.org/10.1007/s41783-018-00372

Narancic T, Cerrone F, Beagan N, O Connor KE (2020) Recent advances in bioplastics: application and biodegradation. Polymers (Basel) 12: 920. https://doi.org/10.3390/polym12040920

Ncube LK, Ude AU, Ogunmuyiwa EN, Zulkifli R, Beas IN (2020) Environmental impact of food packaging materials: a review of contemporary development from conventional plastics to polylactic acid-based materials. Materials (Basel) 13:1-24. https://doi.org/10. 3390/ma13214994

NEA, (2019). Waste management statistics and overall recycling. NEA 1-2, https://www.nea.gov.sg/our-services/waste-management/ waste-statistics-and-overall-recycling. (Accessed 5 May 2021)

North EJ, Halden RU (2013) Plastics and environmental health: the road ahead. Rev Environ Health 28:1-8. https://doi.org/10.1515/reveh2012-0030

O'Dowd K, Nair KM, Forouzandeh P, Mathew S, Grant J, Moran R, Bartlett J, Bird J, Pillai SC (2020) Face masks and respirators in the fight against the COVID-19 pandemic: a review of current materials, advances and future perspectives. Mater (Basel, Switzerland) 13:3363. https://doi.org/10.3390/ma13153363

OECD, (2020). The face mask global value chain in the COVID-19 outbreak: evidence and policy lessons. Oecd, http://www.oecd.org/ coronavirus/policy-responses/the-face-mask-global-value-chain-inthe-covid-19-outbreak-evidence-and-policy-lessons-a4df866d/. (Accessed 9 May 2021)

Oever MVD, Molenveld K, van der Zee M, Bos H, (2017). Bio-based and biodegradable plastics: facts and figures: focus on food packaging in the Netherlands. https://library.wur.nl/WebQuery/wurpubs/519929. (Accessed 9 May 2021)

Okunola AA, Kehinde IO, Oluwaseun A, Olufiropo EA (2019) Public and environmental health effects of plastic wastes disposal: a review. J Toxicol Risk Assess 5:021. https://doi.org/10.23937/2572-4061. 1510021

Onwudili JA, Insura N, Williams PT (2009) Composition of products from the pyrolysis of polyethylene and polystyrene in a closed batch reactor: effects of temperature and residence time. J Anal Appl Pyrolysis 86:293-303. https://doi.org/10.1016/j.jaap.2009.07.008

OSHA, (2020). Control and prevention. Occupational Safety and Health Administration, United States, https://www.osha.gov/coronavirus/ control-prevention. (Accessed 13 May 2021)

Pandey K, Antil R, Saha S, Jacob J, Balavairavan B (2019) Poly(lactic acid)/thermoplastic polyurethane/wood flour composites: evaluation of morphology, thermal, mechanical and biodegradation properties.
Mater Res Express 6:125306. https://doi.org/10.1088/2053-1591/ ab5398

Papania MJ, Zehrung D, Jarrahian C (2018) Technologies to improve immunization. Plotkin's Vaccines 2018:1320-1353.e17. https:// doi.org/10.1016/B978-0-323-35761-6.00068-7

Parashar N, Hait S (2021) Plastics in the time of COVID-19 pandemic: protector or polluter? Sci Total Environ 759:144274. https://doi.org/ 10.1016/j.scitotenv.2020.144274

Park S, Ko Y-S, Lee SJ, Lee C, Woo K, Ko G (2018) Inactivation of influenza A virus via exposure to silver nanoparticle-decorated silica hybrid composites. Environ Sci Pollut Res Int 25:27021-27030. https://doi.org/10.1007/s11356-018-2620-z

Parthasarathi V, Thilagavathi G (2013) Developing antiviral surgical gown using nonwoven fabrics for health care sector. Afr Health Sci 13:327-332. https://doi.org/10.4314/ahs.v13i2.18

Petrosillo N, Viceconte G, Ergonul O, Ippolito G, Petersen E (2020) COVID-19, SARS and MERS: are they closely related? Clin Microbiol Infect 26:729-734. https://doi.org/10.1016/j.cmi.2020. 03.026

Pharmaceutical Technology, (2021). COVID-19 vaccination, https:// www.pharmaceutical-technology.com/covid-19-vaccinationtracker/.(Accessed 15 May 2021)

Pinto Da Costa J, Rocha-Santos TC, Duarte A, (2020). The environmental impacts of plastics and micro-plastics use waste and pollution: $\mathrm{EU}$ and national measures. Eur Union http://www.europarl.europa. eu/RegData/etudes/STUD/2020/658279/IPOL_STU(2020) 658279_EN.pdf. ()

Placon, (2009), Placon implements ecostar material in medical packaging. https://www.placon.com/resources/news/placon-implementsecostar-material-in-medical-packaging/. (Accessed 13 May 2021)

Poerschmann J, Weiner B, Woszidlo S, Koehler R, Kopinke F-D (2015) Hydrothermal carbonization of poly(vinyl chloride). Chemosphere 119:682-689. https://doi.org/10.1016/j.chemosphere.2014.07.058

Potluri P, Needham P, (2005). 6 - Technical textiles for protection, in: Scott, R.A. (Ed.), Textiles for protection, woodhead publishing series in textiles. Woodhead Publishing, 151-175. https://doi.org/10. 1533/9781845690977.1.151

Prata JC, Silva ALP, Walker TR, Duarte AC, Rocha-Santos T (2020) COVID-19 Pandemic repercussions on the use and management of plastics. Environ Sci Technol 54:7760-7765. https://doi.org/10. 1021/acs.est.0c02178

Purkayastha S, Biswal AK, Saha S (2017) Responsive systems in food packaging. J Package Technol Res 1:53-64. https://doi.org/10.1007/ s41783-017-0007-0

Rago YP, Collard F-X, Görgens JF, Surroop D, Mohee R (2020) Torrefaction of biomass and plastic from municipal solid waste streams and their blends: evaluation of interactive effects. Fuel 277:118089. https://doi.org/10.1016/j.fuel.2020.118089

Rahman MH, Akter R, Behl T, Chowdhury MAR, Mohammed M, Bulbul IJ, Elshenawy SE, Kamal MA (2020) COVID-19 outbreak and emerging management through pharmaceutical therapeutic strategy. Curr Pharm Des 26. https://doi.org/10.2174/ 1381612826666200713174140

Rajasekhar C, Kanchi S, (2018). Green nanomaterials for clean environment BT - handbook of ecomaterials, in: Martínez LMT, Kharissova OV, Kharisov BI (Eds.), Springer International Publishing, Cham, 1-18. https://doi.org/10.1007/978-3-319-48281-1_73-1

Ramteke S, Sahu BL (2020) Novel coronavirus disease 2019 (COVID19) pandemic: considerations for the biomedical waste sector in India. Case Stud Chem Environ Eng 2:100029. https://doi.org/10. 1016/j.cscee.2020.100029

Rattner N, (2020). As coronavirus restrictions drag on, Americans shift online spending from stockpiling to entertainment. Cnbc, https:// www.cnbc.com/2020/04/19/coronavirus-what-americans-arebuying-online-while-in-quarantine.html. (Accessed 5 May 2021) 
Research and Market, (2020). Disposable masks - global market trajectory \& analytics. https:/www.researchandmarkets.com/reports/ 5028067/disposable-masks-global-market-trajectory-and. (Accessed 7 May 2021)

Rhee SW (2020) Management of used personal protective equipment and wastes related to COVID-19 in South Korea. Waste Manag Res 38: 820-824. https://doi.org/10.1177/0734242X20933343

Rubio-Romero JC, Pardo-Ferreira MDC, Torrecilla-García JA, CaleroCastro S (2020) Disposable masks: disinfection and sterilization for reuse, and non-certified manufacturing, in the face of shortages during the COVID-19 pandemic. Saf Sci 129:104830. https://doi.org/ 10.1016/j.ssci.2020.104830

Rume T, Islam SMDU (2020) Environmental effects of COVID-19 pandemic and potential strategies of sustainability. Heliyon. https://doi. org/10.1016/j.heliyon.2020.e04965

Saebea D, Ruengrit P, Arpornwichanop A, Patcharavorachot Y (2020) Gasification of plastic waste for synthesis gas production. Energy Rep 6:202-207. https://doi.org/10.1016/j.egyr.2019.08.043

Saha S, Sharma A, Purkayastha S, Pandey K, Dhingra S, (2019). 14 - Bioplastics and biofuel: is it the way in future development for end users? Plastics to energy, plastics design library. William Andrew Publishing, pp. 365-376. https://doi.org/10.1016/B978-0-12813140-4.00014-5

Sahiledengle B (2019) Self-reported healthcare waste segregation practice and its correlate among healthcare workers in hospitals of Southeast Ethiopia. BMC Health Serv Res 19:591. https://doi.org/ 10.1186/s12913-019-4439-9

Saini V, Sikri K, Batra SD, Kalra P, Gautam K (2020) Development of a highly effective low-cost vaporized hydrogen peroxide-based method for disinfection of personal protective equipment for their selective reuse during pandemics. Gut Pathog 12:1-11. https://doi.org/ 10.1186/s13099-020-00367-4

Sanchez-Rexach E, Johnston TG, Jehanno C, Sardon H, Nelson A (2020) Sustainable materials and chemical processes for additive manufacturing. Chem Mater 32:7105-7119. https://doi.org/10. 1021/acs.chemmater.0c02008

Sansaniwal SK, Pal K, Rosen MA, Tyagi SK (2017) Recent advances in the development of biomass gasification technology: a comprehensive review. Renew Sust Energ Rev 72:363-384. https://doi.org/10. 1016/j.rser.2017.01.038

Sarkodie SA, Owusu PA (2020) Impact of COVID-19 pandemic on waste management. Environ Dev Sustain. https://doi.org/10.1007/ s10668-020-00956-y

Scheinberg A, Woolridge A, Humez N, Mavropoulos A, Filho CS, Savino A, Ramola A, 2020. Waste management during the COVID-19 pandemic, ISWA (International Solid Waste Association). https://www.humanitarianlibrary.org/resource/wastemanagement-during-covid-19-pandemic. (Accessed 13 May 2021)

Schnurr REJ, Alboiu V, Chaudhary M, Corbett RA, Quanz ME, Sankar K, Srain HS, Thavarajah V, Xanthos D, Walker TR (2018) Reducing marine pollution from single-use plastics (SUPs): a review. Mar Pollut Bull 137:157-171. https://doi.org/10.1016/j. marpolbul.2018.10.001

Sharma D, Satapathy BK (2019a) Mechanical properties of aliphatic polyester-based structurally engineered composite patches. Macromol Symp 384:1800153. https://doi.org/10.1002/masy. 201800153

Sharma D, Satapathy BK (2019b) Performance evaluation of electrospun nanofibrous mats of Polylactic acid (PLA)/ Poly ( $\varepsilon$ - caprolactone) (PCL) blends. Mater Today Proc 19:188-195. https://doi.org/10. 1016/j.matpr.2019.06.698

Sharma D, Satapathy BK (2020) Optimization and physical performance evaluation of electrospun nanofibrous mats of PLA, PCL and their blends. J Ind Text. https://doi.org/10.1177/1528083720944502

Sharma D, Satapathy BK (2021a) Optimally controlled morphology and physico-mechanical properties of inclusion complex loaded electrospun polyvinyl alcohol based nanofibrous mats for therapeutic applications. J Biomater Sci Polym Ed. https://doi.org/10.1080/ 09205063.2021.1909414

Sharma D, Satapathy BK (2021b) Understanding release kinetics and collapse proof suture retention response of curcumin loaded electrospun mats based on aliphatic polyesters and their blends. J Mech Behav Biomed Mater 120:104556. https://doi.org/10.1016/j. jmbbm.2021.104556

Sharma D, Satapathy BK (2021c) Physicomechanical performance and encapsulation efficiency of $\beta$-cyclodextrin loaded functional electrospun mats based on aliphatic polyesters and their blends. $\mathrm{J}$ Biomater Sci Polym Ed. https://doi.org/10.1080/09205063.2021. 1925393

Sharma D, Satapathy BK (2021d) Fabrication of optimally controlled electrosprayed polymer-free nano-particles of curcumin $/ \beta$ cyclodextrin inclusion complex. Colloids Surf A Physicochem Eng Asp. https://doi.org/10.1016/j.colsurfa.2021.126504

Sharma HB, Vanapalli KR, Cheela VS, Ranjan VP, Jaglan AK, Dubey B, Goel S, Bhattacharya J (2020) Challenges, opportunities, and innovations for effective solid waste management during and post COVID-19 pandemic. Resour Conserv Recycl 162:105052. https://doi.org/10.1016/j.resconrec.2020.105052

Sharma S, Batra S, Gupta S, Sharma VK, Rahman MH, Kamal MA, 2021a. Persons with co-existing neurological disorders: risk analysis, considerations and management in COVID-19 pandemic. CNS Neurol Disord-Drug Targets 20. https://doi.org/10.2174/ 1871527320666210308113457

Sharma D, Saha D, Satapathy BK (2021b) Structurally optimized suture resistant polylactic acid (PLA)/poly ( $€$-caprolactone) (PCL) blend based engineered nanofibrous mats. J Mech Behav Biomed Mater. https://doi.org/10.1016/j.jmbbm.2021.104331

Sharma D, Goel S, Jacob J, Satapathy BK, (2021c). Synthesis, optimal fabrication, and physico-mechanical property evaluation of PCL-bPLLA diblock copolymer-based nanoscale roughness textured electrospun mats. Macromol Mater Eng 2100226. https://doi.org/ 10.1002/mame.202100226.

Sharma D, Mathur VP, Satapathy BK, (2021d). Biodegradable and biocompatible 3D constructs for dental applications: Manufacturing options and perspectives. Ann Biomed Eng. https://doi.org/10. 1007/s10439-021-02839-3

Sharma D, Satapathy BK, (2021e) Polymer substrate based transition metal modified electrospun nanofibrous materials: Current trends in functional applications and challenges. Polym Rev. https://doi. org/10.1080/15583724.2021.1972006

Shashank PM, Prithvi SS, Ramith R (2021) The pathogenicity of MERS$\mathrm{CoV}$, SARS-CoV and SARS-CoV-2: a comparative overview. Res J Biotechnol 16:182-192

Sheldon RA, Norton M (2020) Green chemistry and the plastic pollution challenge: towards a circular economy. Green Chem 22:6310-6322. https://doi.org/10.1039/D0GC02630A

Shereen MA, Khan S, Kazmi A, Bashir N, Siddique R (2020) COVID-19 infection: origin, transmission, and characteristics of human coronaviruses. J Adv Res 24:91-98. https://doi.org/10.1016/j.jare. 2020.03.005

Shokrani A, Loukaides EG, Elias E, Lunt AJG (2020) Exploration of alternative supply chains and distributed manufacturing in response to COVID-19; a case study of medical face shields. Mater Des 192: 108749. https://doi.org/10.1016/j.matdes.2020.108749

Shooshtarian S, Maqsood T, Wong S, Khalfan M, Yang J (2020a) Market development for construction and demolition waste stream in Australia. J Construct Eng Manag Innov 3:220-231. https://doi. org/10.31462/jcemi.2020.03220231

Shooshtarian S, Maqsood T, Khalfan M, Yang R, Wong S (2020b) Landfill levy imposition on construction and demolition waste: Australian stakeholders perceptions. Sustainability 12:4496. https://doi.org/10.3390/su12114496 
Shooshtarian S, Maqsood T, Wong S, Khalfan M, Yang J (2021) Extended producer responsibility in the Australian construction industry. Sustainability 13:620. https://doi.org/10.3390/su13020620

Silva ALP, Prata JC, Walker TR, Duarte AC, Ouyang W, Barcelò D, Rocha-Santos T (2021) Increased plastic pollution due to COVID19 pandemic: challenges and recommendations. Chem Eng J 405: 126683. https://doi.org/10.1016/j.cej.2020.126683

Singh N, Tang Y, Ogunseitan OA (2020) Environmentally sustainable management of used personal protective equipment. Environ Sci Technol 54:8500-8502. https://doi.org/10.1021/acs.est.0c03022

Sinha A, Couderc P (2012) Using OWL ontologies for selective waste sorting and recycling. OWLED-2012, Heraklion, Crete, Greece. hal00924427. https://hal.inria.fr/hal-00924427/document. (Accessed 11 May 2021)

Smith DS (2020). The Covid-19 pandemic's impact on pharma and medical packaging solutions. https://www.dssmith.com/pharma/dssmith-in-pharma/newsroom/2020/11/the-covid-19-pandemicsimpact-on-pharma-and-medical-packaging-solutions. (Accessed 5 May 2021)

SNPA, (2020). COVID-19 emergency: SNPA indications on waste management. https://www.snpambiente.it/2020/03/24/emergenzacovid-19-indicazioni-snpa-sulla-gestione-dei-rifiuti/. (Accessed 7 May 2021)

Softbox (2020), Temperature control packaging systems for the life science industry, https://www.softboxsystems.com/wp-content/ uploads/2018/03/softbox-systems-corporate-brochure-0418.pdf. (Accessed 25 April 2021)

Somani M, Srivastava AN, Gummadivalli SK, Sharma A (2020) Indirect implications of COVID-19 towards sustainable environment: an investigation in Indian context. Bioresour Technol Rep 11:100491. https://doi.org/10.1016/j.biteb.2020.100491

Song JH, Murphy RJ, Narayan R, Davies GBH (2009) Biodegradable and compostable alternatives to conventional plastics. Philos Trans R Soc Lond Ser B Biol Sci 364:2127-2139. https://doi.org/10.1098/ rstb.2008.0289

Sousa AF, Vilela C, Fonseca AC, Matos M, Freire CSR, Gruter G-JM, Coelho JFJ, Silvestre AJD (2015) Biobased polyesters and other polymers from $2\{\}$,5 -furandicarboxylic acid: a tribute to furan excellency. Polym Chem 6:5961-5983. https://doi.org/10.1039/ C5PY00686D

Sterr CM, Nickel I-L, Stranzinger C, Nonnenmacher-Winter CI, Günther F (2021) Medical face masks offer self-protection against aerosols: an evaluation using a practical in vitro approach on a dummy head. PLoS One 16:e0248099. https://doi.org/10.1371/journal.pone. 0248099

Sureka B, Sinha A, Tak V, Garg M, Bhatia P, Bhardwaj P, Nag V, Dutt N, Elhence A, Bhaskar S, Bishnoi A, Chauhan N, Bishnoi N, Misra $S$ (2020) Customized personal protective equipment (PPE): solution to conservation and management of supplies during the coronavirus disease 2019 (COVID-19) pandemic. J Fam Med Prim Care 9: 2180-2182. https://doi.org/10.4103/jfmpc.jfmpc_556_20

Suthar S, Das S, Nagpure A, Madhurantakam C, Tiwari SB, Gahlot P, Tyagi VK (2021) Epidemiology and diagnosis, environmental resources quality and socio-economic perspectives for COVID-19 pandemic. J Environ Manag 280:111700. https://doi.org/10.1016/j. jenvman.2020.111700

Tabish M, Khatoon A, Alkahtani S, Alkahtane A, Alghamdi J, Ahmed SA, Mir SS, Albasher G, Almeer R, Al-Sultan NK, Aljarba NH, AlQahtani WS, Al-Zharani M, Nayak AK, Hasnain MS (2020) Approaches for prevention and environmental management of novel COVID-19. Environ Sci Pollut Res. https://doi.org/10.1007/ s11356-020-10640-3

Tanakasempipat $\mathrm{P},(2020)$. Plastic piles up in Thailand as pandemic efforts sideline pollution fight. Reuters. https://www.reuters.com/ article/us-health-coronavirus-thailand-plastic/plastic-piles-up-in- thailand-as-pandemic-efforts-sideline-pollution-fightidUSKBN22N12W. (Accessed 27 April 2021)

Taylor CHV, Johnson M (2020) SARS-CoV-2. Mater Methods 10:2867. https://doi.org/10.13070/mm.en.10.2867

The Economic Times, (2020). COVID-19 is 10 times more deadly than swine flu: WHO 75128611, https://economictimes.indiatimes.com/ news/international/world-news/covid-19-is-10-times-more-deadlythan-swine-flu-who/articleshow/75128611.cms. (Accessed 27 April 2021)

Thompson RC, Moore CJ, Saal FSV, Swan SH (2009) Plastics, the environment and human health: current consensus and future trends. Philos Trans R Soc B Biol Sci 364:2153-2166. https://doi.org/10. 1098/rstb.2009.0053

Tiseo I, (2021). Global plastic production 1950-2019 Production of plastics worldwide from 1950 to 2019 (in million metric tons ). Statista. https://www.statista.com/statistics/282732/global-production-ofplastics-since-1950/. (Accessed 3 May 2021)

Tiwari A, Patnayak DP, Chander Y, Parsad M, Goyal SM (2006) Survival of two avian respiratory viruses on porous and nonporous surfaces. Avian Dis 50:284-287. https://doi.org/10.1637/7453101205R.1

Toussaint K, (2021). The COVID-19 vaccine rollout is going to create a massive waste management problem, https:/www.fastcompany. com/90601079/the-covid-19-vaccine-rollout-is-going-to-create-amassive-waste-management-problem. (Accessed 5 May 2021)

Tripathi A, Tyagi VK, Vivekanand V, Bose P, Suthar S (2020) Challenges, opportunities and progress in solid waste management during COVID-19 pandemic. Case Stud Chem Environ Eng 2: 100060. https://doi.org/10.1016/j.cscee.2020.100060

UNCTAD, (2020). Growing plastic pollution in wake of COVID-19: how trade policy can help. United Nations Conf. Trade Dev, https:/unctad.org/news/growing-plastic-pollution-wake-covid-19how-trade-policy-can-help. (Accessed 5 May 2021)

UNEP, (2017). UN declares war on ocean plastic. United Nation Environ. Program, https://www.unep.org/news-and-stories/press-release/undeclares-war-ocean-plastic-0. (Accessed 5 May 2021)

UNEP, (2018). Single-use plastics: a roadmap for sustainability, United Nation Environ. Program. https://wedocs.unep.org/handle/20.500. 11822/25496. (Accessed 9 May 2021)

UNEP, (2020). Waste management an essential public service in the fight to beat COVID-19. United Nation Environ. Program, https://www. unep.org/news-and-stories/press-release/waste-managementessential-public-service-fight-beat-covid-19. (Accessed 23 April 2021)

UN-Habitat, (2020). UN Habitat : response to COVID- 19 : strategic guidance on solid waste management. https://unhabitat.org/unhabitat-covid-19-response-plan. (Accessed 29 April 2021)

van Doremalen N, Bushmaker T, Morris DH, Holbrook MG, Gamble A, Williamson BN, Tamin A, Harcourt JL, Thornburg NJ, Gerber SI, Lloyd-Smith JO, de Wit E, Munster VJ (2020) Aerosol and surface stability of HCoV-19 (SARS-CoV-2) compared to SARS-CoV-1. MedRxiv. https://doi.org/10.1101/2020.03.09.20033217

Vanapalli KR, Sharma HB, Ranjan VP, Samal B, Bhattacharya J, Dubey BK, Goel S (2021) Challenges and strategies for effective plastic waste management during and post COVID-19 pandemic. Sci Total Environ 750:141514. https://doi.org/10.1016/j.scitotenv.2020. 141514

Vejerano EP, Leon EC, Holder AL, Marr LC (2014) Characterization of particle emissions and fate of nanomaterials during incineration. Environ Sci Nano 1:133-143. https://doi.org/10.1039/c3en00080j

Wang H, Yang P, Liu K, Guo F, Zhang Y, Zhang G, Jiang C (2008) SARS coronavirus entry into host cells through a novel clathrin- and caveolae-independent endocytic pathway. Cell Res 18:290-301. https://doi.org/10.1038/cr.2008.15

Wang J, Chen Z, Lang X, Wang S, Yang DL, Wu X, Zhou X, Chen Z (2021) Quantitative evaluation of infectious health care wastes from 
numbers of confirmed, suspected and out-patients during COVID19 pandemic: a case study of Wuhan. Waste Manag 126:323-330. https://doi.org/10.1016/j.wasman.2021.03.026

Warnes SL, Little ZR, Keevil CW (2015) Human coronavirus 229E remains infectious on common touch surface materials. MBio 6:1-10. https://doi.org/10.1128/mBio.01697-15

Waste Advantage, (2020). The Impact of COVID-19 on the waste and recycling industry. Advant Waste Recycl. Ind. 1-30, https:// wasteadvantagemag.com/the-impact-of-covid-19-on-the-wasteand-recycling-industry/.(Accessed 3 May 2021)

Weikart C, Langer R, (2020). A new hybrid material for packaging COVID-19 vaccines and other biologics : combining the best of glass and plastic a leader for COVID-19 vaccines by Operation Warp Speed cryo and cold storage container closure integrity. Am Pharm Rev 19-24.

White AO, (2020). Plastic pollution: why chemical recycling could provide a solution. The Conversation, https://theconversation.com/ plastic-pollution-why-chemical-recycling-could-provide-asolution-129917. (Accessed 27 April 2021)

WHO, (1999). Treatment and disposal technologies for health-care waste, https://www.who.int/water_sanitation_health/medicalwaste/ 077to112.pdf. (Accessed 11 May 2021)

WHO, (2011). Sustainability in vaccine packaging, https://www.who.int/ immunization/policy/committees/Sustainability_in_Vaccine Packaging_May11_DRAFT.pdf. (Accessed 3 May 2021)

WHO, (2020a). Shortage of personal protective equipment endangering health workers worldwide. https://www.who.int/news/item/03-032020-shortage-of-personal-protective-equipment-endangeringhealth-workers-worldwide. (Accessed 7 May 2021)

WHO, (2020b). Coronavirus disease 2019 (COVID-19) Situation Report - 82. https://www.who.int/publications/m/item/situation-report\% 2D\%2D-82. (Accessed 27 April 2021)

WHO, (2020c). Coronavirus disease (COVID-19): how is it transmitted? https://www.who.int/news-room/q-a-detail/coronavirus-diseasecovid-19-how-is-it-transmitted. (Accessed 13 May 2021)

WHO, (2020d). Water, sanitation, hygiene, and waste management for SARS-CoV-2, the virus that causes COVID-19, https://www.who. int/publications/i/item/WHO-2019-nCoV-IPC-WASH-2020.4. (Accessed 23 March 2021)

WHO, (2020e). COVID-19 Strategy update, https:/www.who.int/ publications $/ \mathrm{m} /$ item/covid-19-strategy-update. (Accessed 23 April 2021)

WHO, (2020f). Rational use of personal protective equipment for coronavirus disease (COVID-19) and considerations during severe shortages. https://www.who.int/publications/i/item/rational-use-ofpersonal-protective-equipment-for-coronavirus-disease-(covid-19)and-considerations-during-severe-shortages.

Worldometer, (2021). Coronavirus update (live): cases and deaths from COVID-19 virus pandemic. Worldometers. https://www. worldometers.info/coronavirus/.(Accessed 28 March 2021). (Accessed 3 May 2021)

Xanthos D, Walker TR (2017) International policies to reduce plastic marine pollution from single-use plastics (plastic bags and microbeads): a review. Mar Pollut Bull 118:17-26. https://doi.org/ 10.1016/j.marpolbul.2017.02.048

Yao D, Zhang Y, Williams PT, Yang H, Chen H (2018) Co-production of hydrogen and carbon nanotubes from real-world waste plastics: influence of catalyst composition and operational parameters. Appl Catal B Environ 221:584-597. https://doi.org/10.1016/j.apcatb. 2017.09.035

Yesil Y, Bhat GS (2017) Porosity and barrier properties of polyethylene melt-blown nonwovens. J Text Inst 108:1035-1040. https://doi.org/ 10.1080/00405000.2016.1218109

Yip E, Cacioli P (2002) The manufacture of gloves from natural rubber latex. J Allergy Clin Immunol 110:S3-S14. https://doi.org/10.1067/ mai.2002.124499

Zambrano-Monserrate MA, Ruano MA, Sanchez-Alcalde L (2020) Indirect effects of COVID-19 on the environment. Sci Total Environ 728:138813. https://doi.org/10.1016/j.scitotenv.2020. 138813

Zero Waste Europe, 2020. Zero Waste Europe statement on waste management in the context of COVID-19. https://zerowasteeurope.eu/ 2020/04/zero-waste-europe-statement-on-waste-management-inthe-context-of-covid-19/. (Accessed 13 April 2021)

Zhao H, Liu H, Wei G, Wang H, Zhu Y, Zhang R, Yang Y (2021) Comparative life cycle assessment of emergency disposal scenarios for medical waste during the COVID-19 pandemic in China. Waste Manag 126:388-399. https://doi.org/10.1016/j.wasman.2021.03. 034

ZWIA Planning Group, 2004. Zero waste definition. Zero Waste Int. Alliance. https://zwia.org/zero-waste-definition/. (Accessed 3 May 2021)

Publisher's note Springer Nature remains neutral with regard to jurisdictional claims in published maps and institutional affiliations. 